\title{
LA IMPORTANCIA DEL REGIONALISMO EN LA POLITICA COMERCIAL ARGENTINA FRENTE A LA GLOBALIZACIÓN
}

Gabriela Schmidt*

Resumen

El trabajo plantea la alternativa de procurar, ampliar, a la vez que profundizar la inserción de la economía argentina en los flujos internacionales de comercio e inversión. Se reseñan especialmente estrategias implementadas por el país, sus perpectivas de integración preferencial con el bloque latinoamericano del MERCOSUR, por un lado, y por otro, las posibilidades de comerciar con países como Estados Unidos y Canadá a través del ALCA y con la UE.

Palabras clave: comercio internacional - integración - MERCOSUR - ALCA

\section{Abstract}

This paper explains the alternative to try and extend, simultaneously to deepen the argentine economy insertion in international flows of trade and investment. Specially strategies implemented by the country, its perpectivas of preferential integration with the Latin American block of the MERCOSUR, on the one hand, and on the other hand, the possibilities are reviewed of dealing with countries like the United States and Canada through the ALCA and with the UE.

Keywords: international tracre - integration - MERCOSUR - ALCA

\section{INTRODUCCIÓN}

En el mundo globalizado de hoy en día, el comercio exterior aparece cada vez más como un imperativo para los estados nacionales, constituyendo un factor esencial para alcanzar las metas de desarrollo sostenido y bienestar que persiguen. Sin embargo, aunque los modelos proteccionistas a ultranza tienen ya pocos defensores, la liberalización indiscriminada del comercio exterior entraña numerosos peligros y puede terminar ocasionando serios perjuicios a los países que pretenden cambiar bruscamente una estructura económica fuertemente protegida por otra netamente liberalizada. En función de esto, se plantea la alternativa de procurar ampliar y profundizar el proceso de inserción de la economía argentina en los flujos internacionales de comercio e inversión, pero a través de una estrategia cuidadosamente planeada y organizada.

Para ser completa, dicha estrategia debe abarcar todos los frentes del proceso de inserción externa: el unilateral, el multilateral y el regional-preferencial. Cada uno de estos frentes posee características particulares, pero al mismo tiempo comparte con los otros dos un mismo telón de fondo: el de la globalización y las nuevas reglas de juego que la misma determina. El propósito de este trabajo es describir y analizar algunos aspectos de la política comercial de la Argentina en este contexto, poniendo especial énfasis en los esquemas de integración preferencial regionales y subregionales en los que participa la Argentina. 
El trabajo está organizado en tres secciones. En la primera sección se reseñan aspectos generales de la inserción de la Argentina en el mundo, atendiendo especialmente a las políticas respectivas llevadas a cabo unilateralmente por el país y a su participación en el sistema multilateral de comercio del GATT/OMC. En la segunda sección, y principal a la vez, se consideran los hechos y las perspectivas de la integración preferencial y regional de la Argentina, tanto con otros países en desarrollo como con países altamente desarrollados. En el primer caso, la atención recae especialmente en el bloque regional latinoamericano del MERCOSUR, mientras que en el segundo se analizan por un lado las posibilidades de integración con EEUU y Canadá a través del proyecto ALCA, y por el otro las posibilidades de integración con la UE. En la tercera sección se presentan algunas conclusiones.

1. La Globalización y la política comercial argentina sobre una base no discriminatoria: acciones unilaterales y multilaterales

El fenómeno de la globalización, con sus múltiples facetas -económica, cultural, social- ha sufrido fuertes vaivenes a lo largo del siglo XX. Mientras que durante el primer cuarto de siglo se vivió un importante proceso de globalización del cual el país participó activamente, en las décadas de 1930 y 1940 el mundo pasó por uno de sus períodos de mayor cerramiento, durante el cual la Argentina comenzó una política económica de tendencia autárquica que mantuvo hasta fines de los ochenta, sólo interrumpida por dos breves y fallidos intentos de apertura unilateral. Cuando en los años 90 el país puso fin abruptamente a esta política exterior de cerramiento, iniciando un nuevo y veloz proceso de apertura unilateral ${ }^{1}$, se encontró con un mundo que hacía ya varias décadas venía incrementando su interacción e interconexión, hasta alcanzar un nivel de globalización sin precedentes, gracias a los enormes adelantos en los medios de transporte y en las tecnologías de la información y las comunicaciones.

Evidentemente, las repercusiones de este nuevo escenario mundial trascienden ampliamente la esfera económica, influyendo asimismo en lo político e institucional, en lo cultural, en la ecología, en la educación. Hoy en día el grado de influencia e interdependencia entre países es tal que una política nacional autárquica sea en el terreno económico o en cualquier otro, resulta impensable, muy especialmente para los países en desarrollo, entre los que se cuenta la Argentina. Sin embargo, la imposibilidad de llevar adelante una política nacional autárquica de ninguna manera implica la imposibilidad de tener una política nacional. Por el contrario, cuanto más se visualice la globalización como un fenómeno incontrolado, resultado de un conjunto infinitamente grande de fuerzas económicas y de otra índole en permanente interacción, más urge al país trazar un plan de acción coherente, una estrategia que permita su inserción en el escenario globalizado del mundo actual, aprovechando lo más posible las ventajas que éste genera y procurando minimizar los impactos negativos.

Al finalizar la Segunda Guerra Mundial los países más industrializados acordaron la necesidad de poner fin al período de cerramiento económico que se había iniciado con la crisis de 1929, comenzando a tal efecto una serie de ruedas de negociación multilateral. En el transcurso de las mismas negociaron activamente, logrando una importante liberalización de su comercio, sobre todo en las manufacturas. Un poco después, en los años 60, una serie de países del sudeste asiático (Corea, Hong Kong, Indonesia y Taiwán) realizaron una exitosa apertura unilateral en cuyo marco lograron entrar en un sendero de crecimiento sostenido y acortar la brecha del ingreso per cápita con los países desarrollados. Contrariamente, el resto de Asia, África y la mayoría de los países latinoamericanos se auto excluyeron de este proceso, llevando adelante

* Universidad Nacional del Sur y Consejo Nacional de Investigaciones Científicas y Técnicas. CONICET

${ }^{1}$ Al mismo tiempo se ponía en marcha el MERCOSUR, un proceso de integración regional mucho más profundo e importante que otros acuerdos regionales anteriores. 
políticas nacionales relativamente autárquicas y solicitando un tratamiento especial y diferencial en las ruedas de negociación multilateral. Los pocos intentos de apertura unilateral que realizaron hasta mediados de los 80 fracasaron en su mayoría ${ }^{2}$.

Para América Latina, la consecuencia de esto fue que la región acumuló poco capital físico, exportó mucho de su capital humano y aumentó la brecha entre su ingreso per cápita y el de los países más industrializados y desarrollados. Los crecientes desequilibrios fiscales y la mala asignación de los recursos (como consecuencia de un contexto macro plagado de distorsiones) también contribuyeron al estancamiento de la economía, que vino acompañado por un agravamiento de la pobreza y la desigualdad en la distribución del ingreso.

Dentro de este grupo de países, la Argentina tuvo uno de los peores desempeños. En efecto, entre 1970 y 1998 su ingreso per cápita creció apenas un 0,7\%, menos de la mitad del 1,5\% de crecimiento (ya bastante pobre en sí) que tuvo la región en promedio ${ }^{3}$.

En vista de los malos resultados que arrojaba la política de cerramiento, se intentó en tres ocasiones realizar una apertura unilateral: durante el gobierno militar de Onganía (28/06/6608/06/70), nuevamente durante el último gobierno militar (24/04/76-30/10/83) y por último durante el primer gobierno de Carlos S. Menem (08/07/89-14/05/95).

Los dos primeros intentos fracasaron, debido a inconsistencias internas de los respectivos programas de apertura; no obstante, el tercer intento tuvo un éxito bastante importante, a pesar de que, como se verá más adelante, también presentó fallas serias.

El proceso de apertura iniciado en los 90 se dio en tres niveles: el de la negociación multilateral, el de la integración regional y el de la política unilateral. Entre ellos, el último (política unilateral) fue el más relevante, por amplio margen. Efectivamente, en lo tocante a la negociación multilateral, que se dio en el marco de la Rueda Uruguay, se ve más que nada una consolidación de la apertura unilateral, antes que un intercambio significativo de concesiones. En cuanto al rol de la integración regional, cuyo principal elemento fue la puesta en marcha del MERCOSUR, si bien aportó un grado adicional de apertura económica, tuvo una influencia más cualitativa que cuantitativa ${ }^{4}$. En consecuencia, para entender cómo se produjo la reinserción de la Argentina en los flujos del comercio internacional en esos años, se debe analizar ante todo en qué consistieron y qué impacto tuvieron las políticas de apertura unilateral.

Se comenzará con una mirada a la política comercial de importación y exportación de bienes. Durante toda la década del 80 la producción nacional estuvo fuertemente protegida contra la competencia de las importaciones, tanto a través de barreras arancelarias como de licencias a la importación ${ }^{5}$. Con el cambio de gobierno de 1989 se produjo un importante giro al respecto, al eliminarse las licencias de importación y reducirse el arancel promedio en un $50 \%{ }^{6}$. No obstante, y a pesar de que esta nueva política se mantuvo durante toda la década del 90, se implementaron paralelamente varias medidas protectivas, con el fin de "suavizar" los costos del ajuste a las nuevas reglas de la política comercial, sobre todo para los sectores más ineficientes de la

\footnotetext{
${ }^{2}$ En este punto, cabe destacar las excepciones de Chile y China, que comenzaron su apertura a fines de los años 70 con relativo éxito.

${ }^{3}$ Nogués (2001).

${ }^{4}$ La influencia del MERCOSUR se manifestó principalmente en el patrón del comercio y en la evolución del mismo por origen y destino. Se ahondará en esto en la próxima sección.

${ }^{5}$ En efecto, a fines de esa década la Argentina era uno de los países en desarrollo más protegidos.

${ }^{6}$ Los aranceles fueron reducidos en forma escalonada, preservando mayores niveles de protección para los bienes de consumo final, menores para los bienes de capital, y los más bajos para los insumos intermedios.
} 
economía argentina. Entre estas medidas se incluyen los reembolsos ${ }^{7}$, los regímenes especiales para determinadas regiones (ej: régimen especial de Tierra del Fuego) e industrias (ej: régimen automotor), y una variedad de barreras no arancelarias y medidas antidumping aplicadas en forma selectiva. De todos modos, la presión de la competencia externa aumentó considerablemente.

Por el lado de las exportaciones también hubo drásticos cambios. Durante las décadas en que estuvo vigente la política de sustitución de importaciones, la Argentina mantuvo una política de exportación que desincentivaba las exportaciones de los productores locales que tenían ventajas comparativas a nivel internacional (fundamentalmente, los productores agropecuarios), cobrándoles elevados derechos de exportación, a la vez que protegía a las empresas de determinados sectores industriales que buscaba desarrollar, las cuales eran ineficientes en relación a los estándares internacionales, manteniendo cautivo para ellas al mercado interno y otorgándoles además importantes incentivos para que exportaran (a través de desgravaciones impositivas, tasas de interés subsidiadas, tipos de cambio múltiples, etc.). Esta política discriminatoria, que entorpecía la generación de divisas por parte de los sectores eficientes y consumía los recursos por ellos generados en proteger industrias estratégicamente importantes, pero que nunca superaron el estadio de "nacientes", fue desmantelada a principios de los 90, a través de la eliminación de la gran mayoría de los derechos de exportación (manteniendo en valores muy bajos los que subsistieron), la liberalización financiera (que marcó el fin de los subsidios a la exportación a través de tasas de interés privilegiadas) y la unificación del tipo de cambio e introducción de la Convertibilidad. No obstante, se mantuvo la política de reembolsos, otorgándolos en forma escalonada según el sector, con niveles más altos para las manufacturas que para los otros bienes (análogamente al manejo de los aranceles). Siendo el reembolso promedio es inferior al arancel promedio, persistió un sesgo antiexportador, pero muy disminuido con respecto a la situación anterior.

Mientras que la protección en materia de bienes se mide por el nivel de los aranceles y las restricciones cuantitativas, en el caso de los servicios se la puede calcular de la siguiente manera $^{8}$ : en el caso de los servicios transables ${ }^{9}$, por los flujos comerciales en el sector, y en el caso de los servicios no transables (entre los que se incluye la mayor parte de los servicios públicos), por los flujos de inversión extranjera directa destinada a ellos ${ }^{10}$.

Durante los años 90 la Argentina tomó importantes medidas de liberalización en materia de servicios, con el objetivo primordial de modernizar el país luego de varias décadas de disponer de

\footnotetext{
${ }^{7}$ Esta política consistía en darle a los productores locales un reembolso al mismo nivel que los aranceles de importación, a fin de eliminar el sesgo antiexportador generado por aquellos. Como esto entraba en conflicto con las reglas comerciales multilaterales, y además resultaba difícil de sostener desde un punto de vista estrictamente fiscal, no llegó a implementarse en forma total.

${ }^{8}$ Esta metodología fue tomada de Nogués (2001).

${ }^{9}$ A los efectos de hacer un análisis sistemático, los mismos han sido clasificados en cuatro categorías, especificadas en el Acuerdo General Sobre el Comercio de Servicios:

- Cross border supply. Son los servicios que deben ser ofrecidos a través del comercio exterior, cruzando la frontera (ej: llamadas de larga distancia).

- Consumption abroad. Son aquellos servicios que requieren que los consumidores crucen la frontera para consumirlos (ej: servicios turísticos).

- Commercial presence. Son servicios que pueden ser ofrecidos a través de la inversión extranjera directa.

- Presence of natural persons. Servicios que para ser ofrecidos en otro país requieren que individuos concretos del país de origen se trasladen allí. (ej: agentes consultores, actores en una obra de teatro).

${ }^{10}$ En este tipo de servicios la protección se otorga principalmente a través del marco regulatorio y del control de las inversiones.
} 
unos servicios públicos que dejaban mucho que desear, brindados por ineficientes empresas estatales. En efecto, el deterioro de dichos servicios se había acentuado considerablemente durante la década anterior (años 80), de modo que cuando se propuso privatizar su prestación se obtuvo un generalizado apoyo de la ciudadanía.

Entre los servicios que han sido privatizados en los 90 se cuentan: la generación y distribución de energía eléctrica, las comunicaciones y telecomunicaciones, la producción y distribución de gas, la producción de petróleo, químicos y acero, la banca y los seguros. Otros servicios, como la distribución de agua, los ferrocarriles y varios caminos se dieron en concesión por largos períodos.

Como consecuencia de este proceso de desregulación y privatización de los servicios públicos, se generó un importante flujo de inversión extranjera directa, que entre 1993 y 1998 representó entre el 1,2\% (mínimo, 1993) y el 3\% (máximo, 1997) del PBI, y como proporción de los déficits de cuenta corriente, representó un 60\% entre 1992 y 1998. Sin embargo, hubo varias fallas por el camino, incluyendo métodos inadecuados de indexación de tarifas, otorgamiento de posiciones y derechos monopólicos a las empresas privatizadas, y un insuficiente ejercicio de autoridad por parte de los entes reguladores, que en muchos casos no defendieron los derechos de los consumidores como hubieran debido hacerlo. En definitiva, los problemas que se han generado a partir de estas medidas parecen responder fundamentalmente a defectos de la política económica interna y no tanto a las medidas en sí; de hecho, si se compara la calidad de los servicios antes y después de las reformas, se puede afirmar que éstas tuvieron un éxito importante.

Con respecto a las negociaciones multilaterales, los países en desarrollo (y entre ellos la Argentina) tuvieron una participación eminentemente pasiva en las primeras siete ruedas de negociaciones realizadas en el marco del GATT. Sin embargo, al acordarse el lanzamiento de una octava rueda de negociaciones (Rueda Uruguay), decidieron cambiar esta estrategia por otra de negociación activa, con la expectativa de que esto les permitiera obtener beneficiosas concesiones entre sí y de los países industriales. De tal suerte, se acordó negociar sobre una serie de cuestiones que nunca antes se habían considerado en dicho contexto, lo cual confirió a la Rueda Uruguay una complejidad mucho mayor que la de las ruedas anteriores.

Los temas de interés de los países en desarrollo que se pactó negociar fueron la excepción referida a los productos agrícolas y la excepción referida a los productos textiles. Simétricamente, los temas a discutir de interés para los países industriales fueron los derechos de propiedad intelectual, el comercio de servicios y otras “áreas nuevas”.

Dado que en las primeras dos áreas hay una clara ventaja comparativa de los países en desarrollo y en las últimas dos, de los países industriales, se hubiera podido esperar un intercambio balanceado de concesiones. Sin embargo, esto no fue así, fundamentalmente por dos motivos. En primer lugar, en lo relativo a productos agropecuarios y textiles, el fuerte poder de los respectivos lobbies en los países industriales y el escaso poder negociador de los países en desarrollo, determinaron que el acceso de éstos últimos a los mercados de los primeros no aumentara, sino que se mantuviera estable o incluso disminuyera ${ }^{11}$. Por otro lado, los países

\footnotetext{
${ }^{11}$ Los países industriales lograron eludir sus compromisos de liberalización del mercado agropecuario mediante el empleo de diversos trucos o trampas, tales como la elección estratégica de los años base para el cálculo de la reducción arancelaria. En efecto, la base elegida fueron los años 1986-1988, durante los cuales los precios internacionales de los productos agropecuarios fueron relativamente bajos, y por ende los subsidios fueron relativamente elevados. Con esto, los países proteccionistas se aseguraron máximas posibilidades de seguir otorgando subsidios a lo largo del ciclo de precios internacionales. Otro ejemplo de esta conducta desleal puede verse en la puesta en práctica del compromiso de reemplazo de las barreras no arancelarias por aranceles, ya que en la mayoría de los casos los países industriales declararon como
} 
industriales poseen una clara ventaja en propiedad intelectual y servicios (debido a su mayor y anterior desarrollo en estas áreas), lo cual condujo a que las concesiones otorgadas al respecto por los países en desarrollo tuvieran previsiblemente más valor que las recibidas. Además, la definición de las áreas nuevas era para estos últimos países mucho más amplia que la agenda de temas nuevos impulsada por los países industriales, debido a que el acuerdo de la Rueda Uruguay implicaba asumir compromisos no sólo en las áreas nuevas propiamente dichas, sino también en todas aquellas otras que durante la Rueda Tokio habían sido creadas en forma de códigos (a los cuales la mayor parte de los países en desarrollo no había adherido).

Como consecuencia de esta situación, la negociación concluyó con un desbalance en contra de los países en desarrollo, que en algunos casos (como el argentino) fue de una magnitud considerable. Este desbalance puede ser analizado en dos niveles: en términos de concesiones comerciales estrictamente y en términos de costo económico.

El desbalance en términos de concesiones comerciales surge en forma directa de la falta de cumplimiento del principio de reciprocidad (artículo XXVIII bis del GATT), implicando que la Argentina otorgó concesiones por mayor valor de las que recibió. No obstante, en términos del análisis económico, no todo este desbalance generó un costo. En efecto, ciertas medidas aperturistas realizadas por la Argentina en los 90 resultaban imprescindibles, independientemente de lo que hicieran (o dejaran de hacer) en contrapartida los otros países ${ }^{12}$. Más bien, los costos económicos fueron generados por el agresivísimo lobby de los países desarrollados en materia de productos agrícolas (UE) y propiedad intelectual ${ }^{13}$ (EEUU).

Con respecto al tema agrícola, las barreras para el acceso al mercado europeo le generan a la Argentina elevados costos económicos, directos e indirectos. Los costos directos se manifiestan en términos de menores exportaciones, y por ende menor producción y mayor pobreza. Los costos indirectos provienen por una parte, de la caída en los precios mundiales de estos productos que trae como consecuencia el exceso de producción que se produce en respuesta a los subsidios agrícolas. Por otra parte, todo lo anterior contribuye a desestabilizar el entorno macroeconómico, aumentando el riesgo país ${ }^{14}$ y en consecuencia frenando el crecimiento de la generalidad de la economía argentina (lo cual se refleja en la evolución del PBI), ya que las mayores tasas de interés que de ello resultan desincentivan la inversión (ver Gráfico 1 del Apéndice Estadístico).

En relación al tema de la propiedad intelectual, el acuerdo que se ocupa del establecimiento de reglas al respecto es el TRIPS (Agreement on Trade Related to Intellectual

aranceles base de la Rueda Uruguay valores superiores a los equivalentes ad valorem de la cuota a reemplazar. Cabe destacar que Japón es el país industrial que menos recurrió a esta práctica, e incluso en muchos casos declaró aranceles base mucho más bajos que los equivalentes ad valorem.

${ }^{12}$ Por ejemplo, la liberalización del comercio exterior era imprescindible independientemente de que otros países abrieran o no sus mercados a las exportaciones argentinas. Análogo es el caso de la liberalización de los flujos de capital (sobre todo de la IED).

${ }^{13}$ Fundamentalmente en el tema de las patentes farmacéuticas.

${ }^{14}$ El riesgo país es el riesgo de incumplimiento de las obligaciones derivadas de deudas adquiridas por un gobierno central, es decir, de deudas soberanas. Para calcularlo en un caso particular, se toma un patrón de referencia, que convencionalmente está dado por los instrumentos de deuda emitidos por el Tesoro de EEUU, a los cuales se supone prácticamente libres de riesgo de incumplimiento. Un gobierno que emite deuda con mayor riesgo que las obligaciones del Tesoro de EEUU, debe afrontar un diferencial de tasas positivo, que se denomina "prima de riesgo soberano" o "prima de riesgo país". La misma es determinada por el mercado en cada momento del tiempo, teniendo en cuenta una serie de factores objetivos y subjetivos, tales como los indicadores de desempeño macroeconómico, el orden institucional, las actitudes y posiciones de los partidos políticos frente al capital extranjero, las noticias que da la prensa local e internacional, las expectativas de los inversores, etc. 
Property Rights), el cual fue aprobado durante el transcurso de la Rueda Uruguay. El mismo contiene una serie de cláusulas que en conjunto determinan un elevado nivel de protección para este tipo de activos, prácticamente igual al que determinan las legislaciones nacionales en los países más innovadores (que son los países industriales). Con anterioridad a este acuerdo, existía una brecha muy significativa entre los distintos países en lo que hace a reglamentación sobre este tema, observándose una fuerte correlación positiva entre el nivel de desarrollo innovativo de cada país y la cantidad y complejidad de su legislación sobre propiedad intelectual. La causa de esto es que la legislación sobre propiedad intelectual fue evolucionando en los distintos países a la par de la industria, a medida que los agentes innovadores así lo iban requiriendo. A su vez, siendo que la innovación prosperaba al amparo de la creciente protección legal, crecían los incentivos para llevar a cabo actividades innovativas. De este modo ambas actividades (innovación y legislación al respecto) fueron evolucionando en paralelo, dentro de una realimentación positiva que incentivó el crecimiento de ambas.

La pregunta relevante es, entonces, qué efecto cabe esperar que tenga esta igualación artificial de los niveles de protección a la propiedad intelectual sobre las posibilidades de desarrollo innovativo en los países emergentes; si acelerará su dinámica, será neutral a ella o la destruirá. En todo caso, no existen análisis teóricos ni empíricos contundentes que avalen la conveniencia (a nivel del bien común) de homogeneizar el grado de protección.

2. La política comercial argentina sobre una base discriminatoria: políticas de integración regional y preferencial

Como se ha mostrado hasta aquí, las reglas del sistema multilateral de comercio generan beneficios y costos. En el caso de un país como la Argentina, que tiene una clara ventaja comparativa en la producción agropecuaria y alimentaria, dicho sistema le otorga menos acceso a mercados de lo que le hace ceder a otros países, principalmente industrializados, derivando esto en un costo neto, que se manifiesta por diversos canales. Frente a esta situación, la integración regional, sobre todo cuando se produce entre países que se hallan en un estadio similar de desarrollo, aparece como un ámbito en el cual el desequilibrio entre las concesiones otorgadas y recibidas es mucho menor.

Cabe señalar que en la última década se ha producido una fuerte tendencia hacia el regionalismo, evidenciada por la aceleración de la tasa de creación de acuerdos regionales de comercio preferencial (ver Gráfico 2 del Apéndice Estadístico). Esta tendencia ha cristalizado en diversos acuerdos y proyectos de acuerdos de facilitación del comercio sobre una base discriminatoria, en diversas regiones del mundo.

Tal como se ha dado en América, en 1994 se creó el NAFTA (Tratado de Libre Comercio de América del Norte), integrando a EEUU, Canadá y México. En América Latina, se concretó el proyecto del MERCOSUR (Mercado Común del Sur), cuyos miembros son Argentina, Brasil, Uruguay y Paraguay. Además, se trabaja sobre la propuesta de creación de un área de libre comercio hemisférica (ALCA), a partir de la Iniciativa para las Américas lanzada en junio de 1990 por el entonces presidente estadounidense George Bush. También se reactivaron acuerdos de integración regional preexistentes.

En el caso de Asia, el avance se produjo a partir de la ASEAN (Association of Southeast Asian Nations), una iniciativa de integración fundamentalmente política de los países asiáticos. A partir de esta base se planteó un incremento de la integración económica, a través de distintos acuerdos. Uno de estos acuerdos es el AFTA (Asian Free Trade Area), en cuyo marco se proyecta la creación de una zona de libre comercio entre Indonesia, Malasia, Filipinas, Singapur, 
Tailandia, Brunei-Daressalam y Vietnam. Otro acuerdo es el APEC (Asia Pacific Economic Cooperation), cuyo objetivo es facilitar el comercio de bienes y servicios, así como los movimientos de capital y la IED, entre los países del AFTA y algunos otros de la costa del océano Pacífico, a saber: Australia, Chile, China, Hong Kong, Canadá, Corea, México, Nueva Zelanda, Papúa-Nueva Guinea, EEUU y Taiwán. La idea es integrarse sin un tratado formal, es decir, concretar una "integración de hecho".

En Europa, la firma del Tratado de Maastritcht en febrero de 1992 permitió la implementación, en un grupo de los principales países de Europa occidental, de un programa cuyo objetivo es alcanzar una unión económica (incluyendo la unión monetaria, que fue concretada recientemente con la introducción del euro en enero de 1999) y política. La profundización del proceso de integración fue planteada dentro de un esquema gradual, así como la posibilidad de ampliarlo incorporando países de Europa del Este y otros de la región del Mediterráneo. Algunos países de estas dos regiones ya han ingresado recientemente a la Unión Europea.

Esta clara tendencia al regionalismo tiene tanto defensores como detractores, los cuales sustentan su posición con diversos argumentos.

Las críticas ${ }^{15}$ hacia los acuerdos regionales se apoyan sobre todo en dos argumentos principales. Por una parte, estos acuerdos pueden generar desvíos de comercio, con el consiguiente costo neto asociado ${ }^{16}$. Por otra parte, los mismos erosionan uno de los principios básicos del sistema multilateral de comercio, que es el de nación más favorecida (MFN).

Sin embargo, estos acuerdos pueden también contribuir a una mayor liberalización por distintas vías. Por ejemplo, pueden proporcionar un ámbito más apropiado para la negociación de temas sensibles ${ }^{17}$ y al mismo tiempo facilitar las negociaciones multilaterales al reducir el número de participantes (si el bloque tiene suficiente cohesión interna al negociar con terceros) ${ }^{18}$. Además, si bien es cierto que la integración regional erosiona el principio de MFN, el multilateralismo también ocasiona un efecto similar o incluso peor, a través de la aplicación de un número creciente de medidas antidumping.

El debate acerca de la posible compatibilidad o incompatibilidad entre regionalismo y multilatralismo aún no está resuelto. Más allá del mismo, se debe tener muy en cuenta que los autores que consideran al multilateralismo como una forma superior de administrar la política comercial a nivel mundial, han estado muy influenciados por los importantes beneficios que obtuvieron en las siete ruedas anteriores a la Rueda Uruguay los países que negociaron

\footnotetext{
${ }^{15}$ Algunas de las críticas a esta tendencia mundial hacia el regionalismo pueden encontrarse en Bhagwati (1993), Bhagwati y Panagarilla (1996) y Srinivasan (1998).

${ }^{16}$ De acuerdo con los argumentos tradicionales de la teoría del comercio internacional, la liberalización comercial sobre una base no discriminatoria siempre reporta un beneficio neto a los países que la realizan. Sin embargo, en el caso de los acuerdos comerciales preferenciales, los efectos sobre el bienestar económico son ambiguos, dependiendo del peso relativo que tengan los dos efectos inherentes a ella: la creación de comercio y el desvío de comercio. Si la integración conduce al país a reemplazar producción nacional de alto coste por importaciones procedentes de otro país de la unión, tiene lugar una creación de comercio, con la cual el país gana. En cambio, si la integración conduce a reemplazar importaciones más baratas procedentes de un país que no pertenece al acuerdo preferencial por importaciones más caras de un país socio, entonces ocurre una desviación de comercio, con la cual el país pierde. En definitiva, la deseabilidad o no de un acuerdo de comercio preferencial depende de si, en el agregado, los efectos de creación de comercio superan a los de desviación de comercio o viceversa.

${ }^{17}$ Kahler (1995), Höeckamn y Leidy (1993) y Bergsten (1996).

${ }^{18}$ Kahler (1995) y Whinham (1986) y Basevi, Delbano y Mariotti (1995).
} 
activamente en ellas, es decir, los países industrializados. Sin embargo, como ya fue señalado, la historia fue muy distinta en esta última rueda, en la cual muchos países terminaron perjudicados por los resultados obtenidos. Evidentemente, si no se logra un funcionamiento más equilibrado del sistema multilateral de comercio, de manera que otorgue beneficios equiparables a los esfuerzos políticos que demanda, los países que han resultado perjudicados preferirán asociarse con otros que estén dispuestos a equilibrar las concesiones en negociaciones más democráticas, reforzando la tendencia hacia el regionalismo.

2.1 Hechos y perspectivas de la integración preferencial de la Argentina con otros países en desarrollo

a) Marco general de la integración latinoamericana

En la segunda mitad del siglo XIX se desarrolló en América Latina una economía orientada hacia la exportación de productos primarios, sobre todo agropecuarios, que se complementaba con la economía de los países industrializados, configurando el esquema de la división internacional del trabajo ricardiana. Este patrón comercial entró en crisis en los años 30 a raíz de la Gran Depresión que, como es bien sabido, condujo a una ola de aislacionismo y proteccionismo a nivel mundial, a la cual no fue ajena América Latina. En concreto, la región adoptó una política de industrialización mediante sustitución de importaciones ${ }^{19}$, que resultó muy funcional al principio debido al bajo nivel de desarrollo de los países de la región, pero que en las últimas tres décadas fue perdiendo fuerzas y efectividad, y finalmente acabó en el fracaso. Uno de los principales motivos de este desenlace fue que la dinámica de crecimiento de las exportaciones no acompañaba la creciente demanda de importaciones que exigía el proceso de industrialización, lo cual generaba ciclos de desarrollo conocidos como stop-go, en los cuales las fases de crecimiento provocaban déficits comerciales, mientras que la recomposición de reservas tenía lugar durante las fases contractivas. Además, se generaron grandes ineficiencias al abrigo de la protección estatal, que eliminó la necesidad de ser competitivos a nivel internacional, y también como consecuencia del reducido tamaño del mercado interno, que no permitía alcanzar escalas eficientes de producción.

Como resultado de esta situación, a principios de los años 60 se pusieron en marcha varios proyectos de integración entre países latinoamericanos, con el propósito de extender sus políticas nacionales de sustitución de importaciones y disminuir, en la medida posible, la dependencia extrarregional del subcontinente. En este contexto y con estos objetivos, se suscribieron los siguientes acuerdos: la Asociación Latinoamericana de Libre Comercio (ALALC), la Asociación Latinoamericana de Integración (ALADI), el Pacto Andino (actualmente Comunidad Andina de Naciones), el Mercado Común Centroamericano (MCCA) y la Comunidad del Caribe (CARICOM).

Todo este boom integracionista se frenó a fines de los años 70, cuando se hizo evidente el agotamiento del modelo de industrialización basado en la sustitución de importaciones en el

\footnotetext{
${ }^{19}$ Este modelo se enmarcaba dentro de la concepción económica del estructuralismo, desarrollada por la CEPAL, que durante más de 30 años ejerció una fuerte influencia sobre la política económica interna y externa de los países latinoamericanos. Esta escuela de pensamiento defendía la hipótesis de que la planificación a nivel macroeconómico de los sectores determinantes de la estructura económica, acompañado por empresas y monopolios del Estado y una estrategia de sustitución de importaciones, promovería el desarrollo de la industria nacional. De esta manera se esperaba superar el rol de abastecedores de materias primas para los países industrializados.
} 
marco de una economía semicerrada. El mismo se manifestó en una profunda crisis económica, política y social en los países latinoamericanos ${ }^{20}$.

Una de las caras de esta crisis fue la llamada Crisis de la Deuda Externa, que afectó a la totalidad de los países latinoamericanos y cuyo resultado fue un gran retroceso económico y social a lo largo de la década de 1980. Esta “década perdida”, no obstante, fue al mismo tiempo escenario de una profunda transformación económica y política en los países de la región.

Hasta el surgimiento del problema de la deuda externa (a comienzos de los años 80), los gobiernos latinoamericanos habían logrado mantener el modelo industrial de sustitución de importaciones en base a los ingresos obtenidos de las exportaciones agropecuarias y mineras, diversos impuestos y el crédito externo. Este último fue abundante y barato durante los años 70 debido a la gran liquidez internacional de aquel momento ${ }^{21}$. Sin embargo, la recesión mundial de comienzos de los años 80 , que vino acompañada por altas tasas de interés internacionales y bajas estrepitosas en los precios de los productos primarios (principal exportación de los países latinoamericanos) tornó insostenible la situación, que desembocó en la cesación de pagos de la deuda en la mayoría de los países latinoamericanos, siendo México el primero en declararla, en 1982. El desesperado intento por salvar el modelo de desarrollo industrial y económico no hizo más que empeorar la situación, ya que generó déficits fiscales crónicos que engrosaron la deuda estatal y alimentaron tendencias inflacionarias e hiperinflacionarias. Todo esto determinó un retroceso de América Latina en términos de la economía mundial ${ }^{22}$, perdiendo importancia respecto de otras regiones del mundo, como el sudeste asiático.

A fin de superar esta crisis económica y social, los gobiernos latinoamericanos aplicaron diferentes y exigentes políticas económicas. Sin embargo, dichas políticas no tuvieron éxito debido a la falta de una adecuada voluntad política y a la oposición de los sectores que se habían beneficiado con el modelo de sustitución de importaciones. Además, la creciente deuda externa obligó a los países de la región a generar constantes saldos positivos en la balanza comercial, para poder obtener las divisas necesarias para su repago. Esto impulsó un aumento del intercambio comercial con los países industrializados en detrimento del intercambio intra regional. Cada país intentó hallar la salida a la crisis concentrándose en la política económica doméstica, relegando el tema de la integración regional ${ }^{23}$.

Luego de años de falta de inversiones productivas y del consecuente estancamiento económico, la mayoría de los países latinoamericanos comenzó a aplicar una política económica neoliberal, hacia la cual presionaron los organismos internacionales de crédito (Banco Mundial,

${ }^{20}$ La política sustitutiva arrojó resultados muy distintos de los esperados, generando un elevado endeudamiento público y externo, déficit en la cuenta corriente, declive en la productividad y el crecimiento y una elevada inflación, llegando a episodios hiperinflacionarios. El resultado de todo esto fueron diez años de estancamiento en la región.

${ }^{21}$ A raíz de los aumentos en el precio del petróleo ocurridos en los años 70, los países de la OPEP captaron una gran cantidad de divisas, básicamente dólares. Debido a su escaso desarrollo económico, estos países no pudieron absorber tanta liquidez, y por lo tanto la volcaron en la banca europea, que se vio saturada de estos llamados "petrodólares". Debido a su abundancia, estos fondos fueron ofrecidos a tasas muy bajas, que tentaron a los gobernantes latinoamericanos, quienes contrajeron deuda pero no generaron una adecuada capacidad de repago. Hacia fines de los 70, los prestamistas comenzaron a vislumbrar una potencial insolvencia de los deudores latinoamericanos, que condujo a una reticencia creciente a continuar prestándoles dinero e indujo una retirada de capitales colocados en dichos países.

${ }^{22}$ La participación latinoamericana en el comercio mundial cayó del 5,7\% en 1980 al 3,5\% en 1987. Como destino de la IED de los países desarrollados también perdió terreno: en 1980 la región recibía el 60,7\% de la IED efectuada en el mundo en desarrollo; cinco años después dicha participación había caído al 28,2\%.

${ }^{23}$ Una excepción a esta tendencia fue el proceso de integración bilateral llevado a cabo entre Argentina y Brasil, que se inició a mediados de los años 80. 
FMI), otros acreedores externos y diversos actores políticos, económicos y sociales ${ }^{24}$. Con diversos matices en cuanto a su amplitud y profundidad, dicha política estuvo caracterizada por la apertura unilateral de los mercados, la privatización de las empresas públicas, la desregulación y liberalización de las actividades económicas y una reforma del Estado.

En resumen: los esquemas de integración económica regional iniciados durante la década del 60 y principios de la del 70 constituyeron intentos concretos para extender regionalmente el modelo de sustitución de importaciones, pero con el fracaso del mismo, las políticas de integración pasaron a un segundo plano.

Sin embargo, esta situación se revirtió a fines de los 80 y principios de los 90, resurgiendo entonces los esfuerzos integracionistas, aunque con nuevas características y objetivos y en el marco de un contexto internacional muy diferente.

En efecto, con el triunfo de los principios de la economía de mercado a nivel mundial, cambió el eje de la discusión política internacional y se liberaron fuerzas que hasta ese momento habían estado reprimidas por el enfrentamiento entre EEUU y la URSS. Este nuevo escenario mundial se conjugó con un nuevo contexto regional y nacional, generando un marco en el cual los procesos de integración orientados hacia el mercado internacional adquirieron un renovado impulso; no sólo los acuerdos de países latinoamericanos entre sí, sino también iniciativas con la participación de socios ajenos a la región.

Abandonada la sustitución de importaciones, los objetivos de la integración intra-regional cambiaron. Lo que se ha buscado en esta nueva etapa es generar apoyos y sinergias que permitan la inserción competitiva de América Latina en la economía mundial y el fortalecimiento del poder negociador de la región a nivel internacional, junto a un mayor crecimiento económico fundado en el logro de una alta eficiencia y productividad en el empleo de los recursos disponibles. Se pretende en definitiva lograr una industrialización competitiva, mediante la reducción de costos (que podría lograrse mediante la especialización, la producción en escala y la internacionalización con mayor competitividad de las empresas nacionales y regionales) y simultáneamente conformar un mercado de dimensiones atractivas (grande), no sólo para lograr un crecimiento del comercio intra regional sino también para penetrar exitosamente en terceros mercados y competir con otras regiones por las inversiones extranjeras, el financiamiento internacional y el acceso a la tecnología de punta.

En cuanto a la integración con terceros países, un hecho que resulta de fundamental importancia es el cambio de actitud de EEUU con respecto a la región a partir de los años 90, impulsado por su deseo de fortalecer su posición, que había quedado un tanto solitaria en su enfrentamiento comercial con Europa y los países de Asia. Este cambio de actitud se materializó en la perspectiva de una integración hemisférica liderada por EEUU, en el marco de su Iniciativa para las Américas. Dicha iniciativa, presentada en 1990 por el entonces presidente estadounidense George Bush, comprendía tres cuestiones fundamentales: la creación de una zona de libre comercio desde Alaska hasta Tierra del Fuego, la promoción de las inversiones y la eliminación de una parte de la deuda externa latinoamericana. A pesar del evidente cambio de prioridades que han significado para EEUU la lucha contra el terrorismo a partir de los atentados del 11 de septiembre de 2001 y luego la guerra y postguerra en Irak, las negociaciones del ALCA continúan siendo un tema muy relevante para los países de la región.

\footnotetext{
${ }^{24}$ Entre dichos actores se contó la CEPAL, modificando su anterior posición, que era netamente estructuralista.
} 
Volviendo a los esquemas de integración entre países latinoamericanos, en las dos últimas décadas se han podido observar dos fenómenos. Por un lado, el resurgimiento de acuerdos preexistentes, que se encontraban estancados (Pacto Andino, MCCA, CARICOM), y por otro lado la creación de nuevas estructuras de integración (Grupo de los Tres, MERCOSUR). En función de los objetivos de este trabajo, se analizará únicamente el caso del MERCOSUR.

\section{b) El MERCOSUR}

Dentro de un marco de fracasos recurrentes de los diversos procesos integradores, el emprendimiento que iniciaron Brasil y Argentina a mediados de los ochenta y que sentó las bases para el surgimiento del MERCOSUR, se sale de la norma, ya que obtuvo un éxito bastante considerable. La manifestación más visible de este éxito es el notable incremento del comercio intra regional, que ha vuelto a las economías de los países socios mucho más interdependientes. (Ver cuadro 2). Sin embargo, esto mismo hace que las mismas se encuentren más expuestas a los efectos de derrames macroeconómicos, tendiendo a reducir la eficacia de las políticas domésticas y generando una creciente necesidad de concertación de dichas políticas, especialmente de aquellas que influyen sobre los flujos de comercio, los precios y la competitividad entre las economías de la región.

En efecto, las principales dificultades que enfrenta el MERCOSUR surgen de las tensiones que crea la insuficiente coordinación macroeconómica, cuya manifestación más evidente se dio en lo relativo a los planes de estabilización económica seguidos en los 90 por los dos socios principales, y a las diferencias en sus respectivos ritmos de avance en las reformas orientadas hacia el mercado. Es por esto que en este momento, frente a los objetivos de ampliación del MERCOSUR o de su profundización, la prioridad para los países miembros está dada sin duda por la profundización, consistente en el logro de una mayor coordinación macroeconómica, mayor disciplina en materia de incentivos y de armonización fiscal, apertura recíproca en servicios y compras públicas y en asegurar el fiel cumplimiento de lo pactado. Sin embargo, y aunque parezca paradójico, es la dinámica de la ampliación del MERCOSUR, sobre todo en el marco de las negociaciones del ALCA, la que ha planteado la necesidad de imprimir una mayor velocidad a la tarea de profundización, en la medida en que la agenda del ALCA ha avanzado más rápido que el propio MERCOSUR en el tratamiento de diversos temas que hacen a la profundización del acuerdo, tales como disciplinas sobre incentivos a la inversión, compras gubernamentales, servicios, etc. En definitiva, puede decirse que el necesario proceso de armonización y convergencia de las políticas de los países socios es dinámico en el tiempo, presentando alternativamente avances, estancamientos e incluso retrocesos, todo lo cual depende tanto de factores económicos internos a alguno de los socios como de aspectos relativos al propio programa de integración en sí.

Las raíces del actual proceso de integración económica del MERCOSUR se encuentran en los acuerdos firmados entre Brasil y Argentina en la Declaración de Iguazú en 1985. En la misma se expresó la intención de enfrentar en forma coordinada problemas comunes, al mismo tiempo que se fortalecían los sistemas democráticos restablecidos poco tiempo antes y se reducía la desconfianza política mutua y las tensiones militares. En este nuevo intento de cooperación bilateral, que se implementó mediante el Programa de Integración y Cooperación Económica (PICE), las significativas asimetrías en el terreno económico fueron superadas por el consenso en el ámbito de lo político ${ }^{25}$. El PICE, en cuyo diseño se siguieron algunos de los lineamientos de la ALADI, significó un cambio respecto a la aproximación tradicional al problema de la

\footnotetext{
${ }^{25}$ Fernández y González (1996), op.cit.
} 
integración, al estar caracterizado por $^{26}$ el gradualismo y la flexibilidad en su aplicación, la búsqueda del equilibrio del comercio bilateral y la selectividad de sectores en su alcance. El acuerdo no tenía un objetivo de liberalización comercial amplia, ni incluía aspectos referidos a la coordinación de políticas económicas. Su implementación fue llevada a cabo mediante la negociación de protocolos sectoriales.

A pesar de que durante la segunda mitad de la década del 80 tanto Brasil como Argentina se desenvolvieron en un ambiente de alta inestabilidad macroeconómica, el acuerdo permitió que se cumpliera el objetivo primordial de incrementar las relaciones comerciales entre ambos países $^{27}$. Luego, con la firma del Tratado de Integración, Cooperación y Desarrollo, realizada en 1988, cambió el enfoque del proceso de integración entre ambos países, pasando de una simple serie de acuerdos comerciales a una cooperación tendiente al establecimiento de un mercado común. Este objetivo de dar una mayor profundidad y amplitud a la vinculación argentinobrasileña vino acompañado por la inclusión en dicho tratado de temas relativos a la armonización de políticas sectoriales y a la necesidad de coordinar las políticas monetarias, fiscales, cambiarias y de capitales.

Hacia fines de la década del 80, con el cambio de los respectivos gobiernos y la agudización de la inestabilidad macroeconómica, la política económica de ambos países experimentó un importante giro. Los nuevos lineamientos incluían: la liberalización del comercio, la desregulación de los mercados, un significativo repliegue del Estado en la esfera económica (mediante la privatización de empresas estatales y la venta de activos públicos) y el compromiso de mantener una estricta disciplina monetaria y el equilibrio fiscal. Todos estos cambios influyeron en el proceso de integración bilateral, que pasó de un objetivo de área de libre comercio hacia el de gradual conformación de una unión aduanera y eventualmente un mercado común.

Dichas modificaciones quedaron reflejadas en la firma del Acuerdo de Complementación Económica, realizada en el año 1990. En efecto, en dicho acuerdo se abandonaron los principios de flexibilidad, selectividad, equilibrio en el intercambio y gradualismo, al mismo tiempo que se acortaba en tres años el plazo para la entrada en funcionamiento del mercado común, estableciéndose como nueva fecha el año 1995. Asimismo, se acordó la realización de reducciones tarifarias generales, lineales y automáticas, tendientes a la eliminación completa de barreras tarifarias y no tarifarias para el $1^{\circ}$ de enero de 1995. Un aspecto en el que se continuó en la misma línea que antes fue en la insistencia acerca de la necesidad de coordinar y armonizar las políticas macroeconómicas, especialmente aquellas que pudieran tener mayor impacto sobre los flujos de comercio ${ }^{28}$. A tal efecto, se establecieron dos instancias institucionales: el Grupo Mercado Común, encargado de elaborar y proponer medidas para hacer efectivo el acuerdo, y diez Grupos Técnicos, encargados de tratar diversos aspectos del proceso de armonización y coordinación.

Finalmente, en marzo de 1991 se firmó el Tratado de Asunción, mediante el cual se incorporaron al proceso de integración preexistente Paraguay y Uruguay. En dicho tratado, los mandatarios de los cuatro países acordaron la constitución de un mercado común a partir del 31 de diciembre de 1994, que se denominaría MERCOSUR. El mismo comenzaría como una unión aduanera, y debería lograr los siguientes objetivos ${ }^{29}$ : la libre circulación de bienes y servicios

\footnotetext{
${ }^{26}$ Ibidem.

27 En efecto, entre 1985 y 1988 el comercio bilateral se incrementó en cerca de 300 millones de dólares

${ }^{28}$ Fernández y González (1996), op.cit.

${ }^{29}$ Ibidem.
} 
entre los países miembros (lograda mediante la eliminación de derechos aduaneros, aranceles y todo tipo de restricciones no arancelarias); el establecimiento de un arancel externo común (AEC) y la definición de una política comercial común; la armonización de las respectivas legislaciones (a fin de fortalecer el proceso) y finalmente la coordinación de las políticas industriales, tecnológicas y regionales, a fin de hacer converger en forma gradual las políticas macroeconómica, fiscal, monetaria, cambiaria, de servicios, aduanera, de transporte, etc. de los distintos países socios. Con esto se volvía a remarcar la importancia de coordinar las políticas sectoriales y macroeconómicas, a fin de que las condiciones establecidas en el marco del mercado ampliado tuvieran certidumbre y sustentabilidad en el tiempo. De esta manera, las políticas sectoriales y macroeconómicas eran vistas como subsidiarias de las políticas comerciales, cuya coordinación (a través de un proceso de reducción tarifaria automático, progresivo y lineal) fue considerada fundamental para el desarrollo del proceso integracionista.

Sin embargo, el esfuerzo de integración ha sido básicamente arancelario, apoyado en la eliminación de tarifas en el comercio intra regional, el establecimiento de un arancel externo común y la creación de una preferencia arancelaria regional. El desafío de la integración profunda conlleva la necesidad de lograr, además, progresos efectivos y rápidos en otras áreas.

En primer término, es necesario lograr una mayor convergencia macroeconómica, sea a través de la coordinación o de la cooperación. Dadas las dificultades que existen para coordinar efectivamente la política macroeconómica entre los países del bloque, se requiere al menos avanzar en la búsqueda de soluciones cooperativas a fin de resolver los problemas macroeconómicos que se presentan. En este sentido podría resultar útil establecer un mecanismo formal de diálogo macroeconómico periódico, con frecuencia mensual, que incluya a funcionarios de las respectivas administraciones de las Carteras de Economía y de los Bancos Centrales. Otra posibilidad sería crear un Comité Monetario de carácter consultivo al estilo del existente en la UE, a fin de fomentar la coordinación de políticas monetarias y cambiarias entre los estados miembros y de realizar el seguimiento de su situación monetaria y financiera, así como del régimen general de pagos internacionales.

También resulta necesario formular criterios para el abordaje de situaciones de dificultad aguda, tales como una crisis súbita del balance de pagos de alguno de los estados miembros, a fin de asegurar que las medidas cautelares que el estado afectado adopte perjudiquen lo menos posible el funcionamiento del mercado ampliado regional ${ }^{30}$.

Otra necesidad que se impone en la búsqueda de una integración profunda es la formulación de parámetros y tiempos de convergencia macroeconómica, respecto de tasas de inflación, déficit fiscal, deuda pública y tasas de interés de largo plazo, al estilo de los que contiene el Tratado de Maastricht de la UE. Estas metas deben ser concebidas como requisitos mínimos y progresivos, a fin de promover un alto grado de disciplina fiscal y monetaria y de garantizar la estabilidad en la unión aduanera.

También resulta imprescindible idear mecanismos que permitan asegurar el fiel cumplimiento de lo pactado, puesto que el MERCOSUR presenta algunos hechos de incumplimiento que indican claramente la necesidad de fortalecer sus instituciones y reglas, con miras a afianzar la credibilidad y la seguridad jurídica en el mercado ampliado regional ${ }^{31}$.

\footnotetext{
${ }^{30}$ Entre los criterios a aplicar, uno de los más recomendados consiste en establecer la necesidad de informar cuáles serán las medidas cautelares con anterioridad a su entrada en vigor, y el requisito de consulta al sugerido Comité Monetario, quien podrá recomendar modificaciones, suspensiones o la supresión de dichas medidas.

31 Existen tres tipos básicos de incumplimiento: las demoras en la incorporación en el sistema jurídico nacional de las decisiones acordadas a nivel del MERCOSUR por los estados miembros, el incumplimiento
} 
Además de lo anterior, es necesario eliminar los incentivos distorsivos de la competencia. En este aspecto, el MERCOSUR presenta diferencias significativas entre los países miembros en materia de políticas públicas que afectan las condiciones de competencia y la competitividad entre las empresas, las cuales se expresan en diferentes tratamientos fiscal y financiero con respecto a las políticas de promoción de exportaciones, de promoción de la inversión y tecnológica. Al respecto, el Tratado de Asunción (1991) estableció los siguientes objetivos para el MERCOSUR: liberalizar el comercio intrazona, establecer un Arancel Externo Común (AEC), establecer una política comercial común y coordinar y armonizar las políticas económicas de los países miembros. Este último objetivo se demoró, y las asimetrías regulatorias resultantes han redundado en la creación de ventajas artificiales en uno de los dos socios principales (Brasil), que obviamente se traducen en desventajas para el otro (Argentina). Este problema se agrava a medida que aumenta la interdependencia económica entre los estados miembros.

Otra necesidad que se plantea es la de lograr la apertura recíproca en los mercados de servicios y compras públicas. El MERCOSUR necesita imperativamente avanzar en el tratamiento de los temas que hacen a la apertura recíproca de los mercados de servicios (transporte, financieros, seguros, telecomunicaciones, energía, construcción) y de compras públicas, puesto que la diferencia en los niveles de apertura y de acceso a estos mercados generan un desequilibrio en las condiciones de competencia, resultando en mayores costos al interior del mercado regional, y perjudicando a los países más abiertos ${ }^{32}$.

Finalmente, es prioritario definir una estrategia inteligente y coherente de negociaciones externas. En efecto, el MERCOSUR tiene por delante una intensa y compleja agenda de negociaciones externas, incluyendo las negociaciones con el resto de los países de la ALADI, las negociaciones del ALCA y las negociaciones con la UE. Esto enfrenta al MERCOSUR con un doble desafío. Por una parte, no diluir el MERCOSUR, procurando contrarrestar la tendencia al debilitamiento de las preferencias arancelarias intra MERCOSUR mediante avances en la profundización. Por otra parte, establecer un orden y una clara orientación en la agenda de negociaciones externas, puesto que la existencia de varios frentes de negociación simultáneos que no necesariamente se vinculan entre sí, sino que incluso pueden estar enfrentados (ejemplo: negociación con EEUU en el marco del ALCA vs. negociación con la UE) genera un panorama confuso, sobre todo para el sector privado. Además, no se debe perder de vista que el establecimiento de un acuerdo de comercio preferencial con una región determinada será discriminatorio con respecto a otros países o regiones del mundo, por lo que las distintas opciones ameritan un detallado estudio, a fin de evitar el riesgo de eliminar a priori socios potencialmente muy convenientes (ej: países con los que la Argentina no ha tenido históricamente una vinculación importante, pero que en la actualidad se perfilan con un significativo potencial económico, como es el caso de China y diversos países de la región del Pacífico Asiático).

Todo esto cobra mayor relevancia si se visualiza al MERCOSUR no como objetivo final de la política de integración de la Argentina, sino más bien como un poderoso medio para facilitar la concreción de otros acuerdos ventajosos. Esto es coherente con la idea de que, bien aprovechada, la pertenencia al bloque puede ser útil para mejorar las posibilidades de nuestra economía de integrarse con países ricos y dinámicos de una manera ventajosa, pero si no fuera posible lograr este objetivo desde el MERCOSUR, se deberán intentar otras vías.

de disciplinas ya acordadas y consensuadas a nivel del MERCOSUR y la toma de decisiones en forma unilateral.

${ }^{32}$ La Argentina es el único país del MERCOSUR que posee un régimen abierto tanto en materia de servicios como de compras públicas, mientras que los restantes estados miembros conservan regulaciones específicas, que en lo relativo a compras públicas otorgan un trato preferencial a los proveedores nacionales, y en materia de servicios establecen barreras a la entrada en diversos mercados. 


\subsection{Hechos y perspectivas de la integración de la Argentina con países desarrollados}

Si bien el MERCOSUR ha tenido efectos económicos y políticos positivos para los países miembros, la evidencia empírica sugiere, de una manera bastante clara, que los procesos de integración entre países en desarrollo no tienden a converger a los niveles de ingreso de los países industriales. En cambio, en los casos de integración de países en desarrollo con países industriales, la experiencia muestra en forma bastante concluyente que existen fuerzas de convergencia, aunque las mismas no son automáticas, sino que requieren de la aplicación de reformas estructurales adecuadas para poder funcionar ${ }^{33}$.

Se han propuesto diversos motivos que pueden conducir a la convergencia de ingresos cuando un país en desarrollo se integra con otro con un grado de desarrollo relativo superior.

Por una parte, según la teoría de las ventajas comparativas los beneficios del comercio son más importantes cuando éste se produce entre países que tienen una importante divergencia en sus dotaciones de factores, y tienden a desaparecer cuanto más similares son. Si bien es cierto que esta teoría se basa en muchos supuestos simplificadores, ha demostrado tener un importante poder explicativo respecto de los flujos comerciales. Siguiendo este argumento, para un país como la Argentina sería más ventajoso el intercambio comercial con EEUU o la UE, cuyas dotaciones relativas de capital y trabajo son bastante diferentes de la argentina, que con Brasil, que tiene una relación capital-trabajo más similar a aquélla ${ }^{34}$.

Además, la integración con un país más rico en capital, tanto físico como humano, puede generar un proceso de relocalización industrial y flujos de IED, en la medida en que la retribución a algún factor (típicamente el trabajo) sea más baja en el país más pobre, permitiendo un ahorro significativo de costes. Como ejemplo de esto puede citarse el caso mexicano, para el cual existen evidencias claras de que el NAFTA generó una relocalización de plantas desde EEUU hacia México ${ }^{35}$.

Otro factor a considerar es la posibilidad de que a través de los flujos comerciales se transfieran conocimientos y tecnología ${ }^{36}$. Si esta hipótesis es cierta, los socios comerciales de un país que tiene un determinado stock de conocimientos accederán al mismo a través de sus importaciones desde aquél, de lo cual se deriva que los países más abiertos (en términos de la relación importaciones a PBI), y que tienden a comerciar más con los países que tienen mayores conocimientos productivos acumulados, son los que más se beneficiarán del conocimiento generado en el exterior y de su impacto positivo sobre la productividad.

\footnotetext{
${ }^{33}$ Algunos casos de estudio de los años recientes que avalan la existencia de convergencia cuando países más pobres se integran con otros más desarrollados, son los de España, Irlanda y Portugal. Estos países tenían en la década del 80 un ingreso per cápita correspondiente al 49\%, 61\% y 27\% del de los países de la UE, respectivamente. Para fines de los años 90, estas diferencias se habían reducido a 67\%, 91\% y 38\%. Como ejemplo de que dicha convergencia, si bien existe, no es automática, se puede citar el caso de Grecia, que pese a haber ingresado a la UE antes que España y Portugal, no ha convergido aún porque no realizó los ajustes necesarios para poder beneficiarse de los flujos de comercio e inversión. Dentro de América Latina, un interesante caso de estudio está dado por México y su evolución antes y después del ingreso al NAFTA.

${ }^{34}$ Para que esto sea válido debe estar garantizado un amplio acceso a mercados.

${ }^{35}$ Ver Feenstra y Hanson (1997), citado en Consejo Empresario Argentino (2001).

${ }^{36}$ Ver Coe, Helpman y Hoffmaister (1997), Eaton y Kortum (1997a, 1997b y 2001), entre otros trabajos al respecto.
} 
Finalmente, muchas veces la integración con un país más desarrollado -y más establerepercute positivamente sobre la percepción que el resto del mundo tiene del país en desarrollo en cuestión. En el caso concreto de los países del MERCOSUR, es necesario tener en cuenta que son economías emergentes, y por lo tanto sumamente volátiles y vulnerables a las crisis financieras externas, lo cual se agrava por los efectos de contagio que se dan entre ellos. Bajo estas condiciones, la integración con un país rico tendría al menos dos efectos positivos. Por un lado, la simple firma de una relación contractual, aunque sólo sea en términos comerciales, mejoraría las expectativas financieras. Por otro lado, si las negociaciones son realizadas adecuadamente, un acuerdo con un país rico se traducirá de manera más o menos rápida en un aumento de la exportaciones y de las expectativas de crecimiento. Estas dos cosas mejorarán la percepción que los inversores tienen de la economía en cuestión, impulsando una caída en el riesgo país.

De este análisis surge que existen potenciales ventajas en una asociación con países ricos, entonces cabe preguntarse: ¿Cuáles son las posibilidades en este sentido para los países del MERCOSUR?

Básicamente, dichas posibilidades de integración existen con EEUU y Canadá por un lado, y por otro lado con la UE. Por ende, en esta sección se analizarán las perspectivas de vinculación de la Argentina con ambas regiones. No obstante, el énfasis recaerá sobre el estudio de las posibilidades de integración con EEUU y Canadá, una posibilidad que en este momento se encuentra planteada en forma explícita y concreta a través del proyecto ALCA, a diferencia de lo que ocurre en el caso europeo, donde no existe aún un marco formal definido para la eventual generación de un acuerdo integracionista y, debido a la persistencia del fuerte proteccionismo agrícola de la UE, no se vislumbra que el mismo pueda concretarse en el futuro cercano.

\section{a) Un proyecto de integración hemisférica: el ALCA}

El lanzamiento de la iniciativa ALCA puede ser visto como una respuesta de EEUU frente al nuevo escenario regional y mundial que se planteó en los años 90. En efecto, el ALCA se perfila como una oportunidad sin precedentes para los exportadores e inversores de EEUU para consolidar y/o ampliar su participación en el mercado latinoamericano, que en 1998 representaba casi el $20 \%$ de sus ventas al mundo (frente a un 13\% que representaba a fines de los 80 ) y un $20 \%$ de las ganancias netas obtenidas en el extranjero por filiales de empresas estadounidenses. De hecho, a lo largo de la década del 90 América Latina se constituyó en el mercado de mayor dinamismo para los exportadores estadounidenses, que casi triplicaron sus ventas a la región en el período 1990-1997 (ver Cuadro 2 del Apéndice Estadístico). Además, América del Sur y Central es una de las pocas regiones del planeta con las que EEUU mantiene actualmente un intercambio comercial favorable, y también tiene una importancia significativa desde el punto de vista de sus inversiones directas ${ }^{37}$ (ver Cuadro 3 del Apéndice Estadístico).

Las motivaciones latinoamericanas para participar en el proyecto ALCA varían según el país, obedeciendo a distintos factores, tales como la participación que EEUU tiene actualmente como mercado destino de sus exportaciones, la importancia relativa que los mercados externos en general tienen para la economía en cuestión, el tipo de productos que componen su oferta exportable y el nivel de los aranceles y de las barreras para-arancelarias vigentes en la actualidad. Además se deben tener en cuenta las grandes asimetrías de toda índole que existen en la región: desde las profundas brechas en la cantidad de población y en el ingreso per cápita, hasta las

\footnotetext{
${ }^{37}$ En los años 90 EEUU se convirtió en el principal inversor extranjero en México y en los países del MERCOSUR, de América Central y de la Comunidad Andina, superando ampliamente la participación que a este respecto alcanzan los países europeos o Japón.
} 
divergencias en los marcos regulatorios y en las políticas nacionales en vigencia. Sin embargo, más allá de las peculiaridades nacionales o regionales, es interesante remarcar que el ALCA aparece como una inédita invitación de EEUU hacia los países latinoamericanos, a efectos de alcanzar un acuerdo comercial negociado, consensuado y de características plurilaterales. De este modo, el ALCA marca un giro en la relación entre EEUU y los países latinoamericanos, abriendo la posibilidad para estos últimos de negociar un acuerdo entre pares con las potencias de América del Norte, basado en un criterio de adhesión voluntaria y de convergencia de intereses.

Desde un punto de vista estrictamente económico, los beneficios que los países latinoamericanos podrían obtener del ALCA se relacionan con la tradicional agenda de acceso a mercados, que abarca desde la obtención de preferencias comerciales respecto de terceros países hasta la eliminación del escalonamiento tarifario y de las barreras no arancelarias que actualmente impiden o limitan el ingreso de diferentes productos al mercado norteamericano. En concreto, el ALCA contribuiría a mejorar las condiciones de acceso al gran mercado estadounidense para los países latinoamericanos. Por otra parte, no participar en el acuerdo, especialmente si un número importante de países de la región sí lo hace, podría significar para los países que adopten dicha postura la pérdida de mercados en favor de EEUU y de aquellos países latinoamericanos que participen del ALCA, así como la auto exclusión de los flujos de IED hemisféricos (sobre todo de los provenientes de EEUU).

Además de estas motivaciones de naturaleza económica, existen otras de carácter estratégico. Por ejemplo, un acuerdo de este tipo podría contribuir a mejorar la reputación y la credibilidad de los países latinoamericanos en los mercados financieros internacionales. Al mismo tiempo podría actuar como reaseguro de los respectivos procesos de reforma económica.

En definitiva, si el acuerdo del ALCA se concreta de manera equilibrada, podría servir para complementar o incluso potenciar las políticas de apertura y de reforma económica que los países de la región han puesto en marcha en los últimos años del siglo XX. Sin embargo, junto a los beneficios potenciales del ALCA se plantean riesgos y desafíos para varios sectores productivos de la región ${ }^{38}$.

Haciendo un balance del ALCA, desde el lanzamiento del proyecto hasta el momento actual, aparecen algunos logros interesantes junto a importantes falencias y desafíos a futuro. Por el lado de los logros o beneficios del ALCA, se tiene que el proyecto refleja una importante convergencia de intereses, que no existía diez años antes de su lanzamiento, y además el proceso hemisférico está creando un legado para los países del continente, que será de un gran valor aún si no llega a concretarse el ALCA, dado que las bases de datos constituyen una sistematización útil de información comercial hemisférica no disponible hasta el momento y el trabajo preparatorio y de negociación ha contribuido a que los países se enfoquen en los temas "nuevos" de una economía mundial globalizada y en las disciplinas de la OMC.

Por su parte, las principales falencias del proyecto están dadas por la limitada capacidad del ejecutivo estadounidense para agilizar la firma de acuerdos de libre comercio, debido a la no

\footnotetext{
${ }^{38}$ En Brasil, por ejemplo, tanto los empresarios como la dirigencia política consideran que las ganancias obtenibles a partir del ALCA no son espectaculares, mientras que los costos podrían ser importantes en ciertos sectores, como el de las maquinarias eléctricas y no eléctricas, los bienes de consumo electrónico, los equipos de trasporte, los productos químicos, los productos informáticos y ciertos servicios. Otro sector que seguramente se vería perjudicado, tanto en Brasil como en la Argentina, es el agrícola, puesto que tendría que competir con producciones que se han desarrollado en EEUU gracias a los enormes subsidios gubernamentales.
} 
aprobación del fast track ${ }^{39}$, las posiciones divergentes de EEUU (principal promotor del proyecto hemisférico) y los países del MERCOSUR, sobre todo Brasil (principal contrapeso de EEUU en el Cono Sur), una desmedida predominancia del trabajo técnico sobre la visión política y por el hecho de que, ya a una década del nacimiento del proyecto (desde la Cumbre de Miami, en 1994), si bien se han logrado algunos consensos importantes, subsisten muchos interrogantes sobre los mecanismos concretos que se establecerán para cumplir con los mismos y las negociaciones atraviesan una fase de relativo estancamiento.

Más allá de estas cuestiones, un aspecto de suma importancia a analizar son las estrategias que los distintos participantes del proyecto ALCA han implementado frente al mismo. Los países del MERCOSUR, que son los que especialmente interesa estudiar aquí, visualizan el ALCA como un interesante proyecto de largo plazo, sin perder de vista que su prioridad actual es completar y perfeccionar el funcionamiento de su propia integración, para lo cual necesitan retrasar todo lo posible el comienzo del ALCA. Muy distinta es la situación de los países caribeños y centroamericanos, los cuales han mostrado un particular interés por consolidar su posición de socios naturales de EEUU y el trato preferencial del que actualmente gozan en términos de acceso al mercado norteamericano, lo cual los hace partidarios de una concreción lo más rápida posible del ALCA, contemplando además un trato preferencial en función del pequeño tamaño y bajo desarrollo de sus economías. En el caso de México, el principal objetivo en relación al ALCA es consolidar su participación en el NAFTA, a la vez que intenta aprovechar su posición como eje entre la América Latina y la América Anglosajona para diversificar, al menos parcialmente, su comercio, que está cada vez más concentrado en el mercado de EEUU. También Canadá visualiza en el ALCA una posibilidad de despegarse de algún modo de EEUU y acrecentar sus hoy tenues lazos con los países latinoamericanos. Finalmente, en EEUU, país impulsor del proyecto desde sus inicios, el debate interno acerca de la conveniencia de avanzar en la conformación de un área de libe comercio hemisférica aún está lejos de haber sido resuelto, coexistiendo posturas encontradas.

Todo esto evidencia que el proyecto ALCA se desarrolla en un escenario difícil, en el que coexisten múltiples estrategias, condiciones iniciales y motivaciones, lo cual obstaculiza el avance de las negociaciones y plantea incertidumbre con respecto a la forma final que tendrá el ALCA, en caso de que llegue a concretarse. Pero sobre todo, la dificultad más seria que enfrenta el proyecto es probablemente la asimétrica distribución del poder negociador. En este sentido, resulta importante destacar que debido a la existencia del MERCOSUR, la negociación del ALCA ha quedado planteada el términos relativamente bipolares, configurando un esquema

\footnotetext{
${ }^{39}$ En EEUU, a diferencia de lo que pasa en la mayoría de los países latinoamericanos, el Congreso tiene un fuerte rol en la formulación de la política comercial. Esto, evidentemente, entorpece sus negociaciones con otros países, debido a que un Parlamento es un órgano poco apto, por sus características intrínsecas, para tratar con otras naciones. A raíz de la dificultades que surgen de esta característica institucional interna, en 1974 EEUU aprobó un procedimiento institucional llamado Fast Track Authority (vía rápida), a través del cual el Congreso concede al Poder Ejecutivo autorización temporaria y eventualmente sujeta a ciertos requisitos para negociar acuerdos y concesiones comerciales con otros países o con bloques, tanto en forma individual como multilateral. El pre-acuerdo que se alcance de este modo debe ser posteriormente sometido a la votación dentro de un plazo de noventa días legislativos y como paquete cerrado, implicando esto último que el Congreso podrá aceptarlo o rechazarlo, pero no modificar sus términos particulares.

Como surge del párrafo anterior, el fast track es una cuestión de la política interna estadounidense, y su interés para los demás países involucrados en las negociaciones del ALCA radica simplemente en la fuerte gravitación política y económica que EEUU tiene en el continente y en el mundo. El hecho concreto es que, de continuar la negativa del Congreso a aprobar la vía rápida, el presidente estadounidense puede perder la credibilidad y el liderazgo en el proyecto ALCA, de lo cual se sigue que es muy difícil que las negociaciones puedan progresar sin ese aval político del Congreso estadounidense.
} 
bastante alejado del simple proceso de paulatina adhesión de los distintos países latinoamericanos al NAFTA, que muchos analistas habían anticipado cuando se lanzó el proyecto del ALCA ${ }^{40}$.

En el plano estrictamente comercial, se observan asimetrías en las políticas nacionales latinoamericanas en función de la mayor o menor cercanía geográfica con respecto a EEUU. En efecto, es interesante observar cómo los países geográficamente más próximos a EEUU (los de Norte y Centro América, e incluso los del norte de Sudamérica) son casi sin excepciones fuertemente dependientes del mercado norteamericano para la colocación de sus exportaciones. Por el contrario, más hacia el sur, la estructura regional del comercio de los diferentes países se va diversificando, y por ende resulta menos dependiente del mercado estadounidense. Entre estos últimos países figuran los cuatro miembros del MERCOSUR junto a Chile, Perú, Bolivia y Colombia. Estos países comercialmente más diversificados (los global traders), también pueden separarse en dos subgrupos: los países exportadores de materias primas (como Chile, Bolivia y Perú) y los países con un patrón de comercio más diversificado, como Brasil y Argentina. Ambos grupos tienen en común el hecho de que su escaso nivel de complementación económica con EEUU implica que su eventual asociación comercial con dicho país no podría ser caracterizada como una sociedad natural. Finalmente, los países del Cono Sur son los que se encuentran en una situación más singular frente al proceso de negociación del ALCA, con costos y beneficios potenciales que difieren sustancialmente de los que enfrentan los restantes países participantes.

Desde la perspectiva del poder negociador, salta a la vista que en el caso de las economías estructuralmente dependientes de EEUU éste es muy escaso, y va aumentando a la par de la diversificación regional del comercio. En el caso concreto de los países del MERCOSUR, el simple hecho de tener abiertas otras alternativas de negociación extra regionales, como por ejemplo las oportunidades de realizar acuerdos con la UE, contribuye de algún modo a mejorar su margen de maniobra en los distintos foros. Otros ámbitos en los que también existen importantes asimetrías entre EEUU y sus potenciales socios latinoamericanos son el de la productividad (donde existe una marcada ventaja de EEUU) ${ }^{41}$ y el arancelario. En este último EEUU y Canadá parecieran tener poco que ofrecer a América Latina, puesto que la tarifa promedio es sustancialmente menor en estos dos países en relación al resto de los posibles integrantes del ALCA, con lo cual la relación costo/beneficio derivada de un proceso de liberalización tarifaria recíproca sería mayor para los países latinoamericanos que para EEUU y Canadá) ${ }^{42}$.

Finalmente, una de las principales reivindicaciones acerca de la cual los países del MERCOSUR en general y la Argentina en particular han insistido desde el inicio de las negociaciones del ALCA, se refiere a la necesidad de implementar algún tipo de mecanismo tendiente a eliminar, o al menos limitar, los regímenes de subsidios y ayudas especiales que algunos países del continente, sobre todo EEUU y Canadá, mantienen en relación a su sector agrícola.

En efecto, este tipo de mecanismos perjudica a los países latinoamericanos de distintas maneras. Por una parte, impide el ingreso de exportaciones de productos agropecuarios del Cono Sur a los mercados de América del Norte. Además, en algunos casos los ha desplazado de terceros mercados del hemisferio, tales como los de Centroamérica y el Caribe, México, Venezuela e incluso Brasil. Finalmente, ha provocado caídas en los precios internacionales de los

\footnotetext{
${ }^{40}$ Sin embargo, la fortaleza con que el MERCOSUR pretende mantener su posición frente a EEUU se ve severamente cuestionada cuando se mira la realidad de los países miembros, signada por la crisis financiera y la inestabilidad económica y política.

${ }^{41}$ Ver Cuadro 4 del Apéndice Estadístico.

${ }^{42}$ Ver Cuadro 5 del Apéndice Estadístico.
} 
productos subsidiados y/o exportados a precios de dumping, lo cual evidentemente perjudica a los exportadores eficientes.

En realidad, el interés argentino por discutir este tema con EEUU es anterior al lanzamiento del ALCA, pero dado que las gestiones bilaterales entre ambos países no se materializaron en compromisos concretos por parte de EEUU (ni tampoco con Canadá) ${ }^{43}$, la Argentina ha intentado aprovechar la negociación del ALCA para reclamar un compromiso de EEUU y Canadá en el sentido de no exportar subsidios agrícolas ni vender su producción a precios de dumping en el hemisferio ${ }^{44}$. Por último, es importante señalar que también ha habido movilización al respecto de este tema desde el sector privado de la región ${ }^{45}$.

A modo de conclusión sobre el tema del ALCA, puede decirse que se trata de un proyecto que, en caso de llegar a concretarse, promete interesantes beneficios pero también implica riesgos importantes para América Latina, el MERCOSUR y la Argentina en particular.

Comenzando por los aspectos positivos, se advierte que la negociación hemisférica podría ser un ámbito apto para consolidar las preferencias de las que actualmente gozan algunas exportaciones latinoamericanas en el mercado de EEUU, aunque en forma más o menos precaria. También permitiría lograr mejores condiciones de acceso para productos o sectores que actualmente tienen vedado su ingreso al mismo, o bien ingresan en cantidades limitadas o en condiciones de fuerte incertidumbre. Del mismo modo, cuestiones tales como la reducción y/o eliminación de los subsidios que EEUU y Canadá mantienen en favor de sus sectores agrícolas, y la creación de un ambiente institucional que favorezca el flujo de inversiones tanto desde EEUU hacia el Cono Sur como desde el Cono Sur hacia el resto de América Latina, también son terrenos en los que estos países pueden llegar a obtener beneficios a partir del ALCA.

Sin embargo, como se señaló previamente, el ALCA también involucra riesgos para la región. Por una parte, el proceso de integración con un socio de la magnitud de EEUU podría generar una erosión de las preferencias que los países de América Latina poseen actualmente en sus respectivos mercados regionales (MERCOSUR, Comunidad Andina de Naciones, MCCA, etc.), con negativas implicancias sobre sus actuales corrientes de exportaciones intra-regionales, que están caracterizadas por su relativamente alto grado de skill intensity. Además, el hecho de que la negociación del ALCA incluya temas que van más allá del plano estrictamente comercial, tales como inversiones, propiedad intelectual, compras gubernamentales o servicios, podría contribuir a alejar aún más a los países del MERCOSUR de eventuales socios no tradicionales (ej: China y otros países del Pacífico Asiático). Tampoco debe perderse de vista que, mientras que los efectos esperables en términos de creación de comercio no parecen ser en principio muy significativos, sí aparentan serlo las pérdidas derivadas del desvío de actuales flujos de comercio en perjuicio de proveedores extra-regionales, los cuales podrían adoptar algún tipo de represalias, formales o informales. Finalmente, es interesante remarcar una dimensión frecuentemente

\footnotetext{
${ }^{43}$ No obstante, las ventas de ambos países de productos agrícolas a países de Sudamérica registraron una drástica disminución.

${ }^{44}$ El reclamo argentino fue presentado formalmente en 1995 en el marco del grupo de trabajo sobre subsidios, antidumping y derechos compensatorios, a través de un documento-propuesta titulado "América Libre de Subsidios”. En el mismo se sugería una serie de mecanismos comerciales y jurídicos orientados al logro de dicho objetivo.

${ }^{45}$ Un ejemplo de esto se observó en el marco del III Foro Empresarial de las Américas, realizado en Belo Horizonte en mayo de 1997, en el que varias entidades representativas del agro de los cuatro países del MERCOSUR presentaron un documento en el que se reclamaba el compromiso de los países del continente de reducir sus aranceles sobre los respectivos productos agrícolas sensibles y que los países desarrollados del continente eliminaran todos los subsidios (no sólo los aplicables a la exportación) que distorsionan el comercio en el sector agrícola.
} 
olvidada de la cuestión, consistente en que la incertidumbre que actualmente existe en todo el hemisferio tanto acerca de la concreción del ALCA en lo relativo tanto a tiempos como a sus eventuales alcances y/o limitaciones, sin duda introduce incertidumbre en el proceso de toma de decisiones de las empresas que operan en la región, al impedirles prever las reglas de juego que deberán enfrentar en un futuro (aranceles, políticas de competencia, marcos regulatorios, disciplinas comerciales, etc.). Este es, sin duda, un problema bastante serio, puesto que en la toma de decisiones económicas, la incertidumbre es siempre uno de los peores ingredientes.

Para terminar de completar este panorama de luces y sombras, resta señalar que también existen cuestiones ambiguas, es decir, cuestiones respecto de las cuales no se puede prever si el ALCA generará beneficios o perjuicios para la región. Quizá el más relevante de estos puntos ambiguos sea si el proceso de desgravación arancelaria a escala continental implicará un incremento o una disminución de las inversiones norteamericanas en el Cono Sur. En efecto, los acuerdos a alcanzar en el marco del ALCA sobre el tratamiento de la inversión o sobre los regímenes de compras gubernamentales podrían contribuir a dinamizar los flujos de IED intrahemisféricos. Sin embargo, la eliminación de las barreras al comercio abriría la posibilidad para que las empresas norteamericanas concentren sus actividades en determinados países o regiones del continente a fin de aprovechar economías de escala, sustituyendo así sus actuales inversiones directas (que son generadas por la necesidad de "saltar" el arancel nacional) por nuevos flujos de comercio intra-hemisféricos. Si esto ocurre, las eventuales ganancias dinámicas del proceso de integración en materia de producción, comercio y empleo podrían tender a concentrarse en determinados países o regiones, en detrimento de otros.

\section{b) Un posible acuerdo de integración con la Unión Europea}

Un interesante derivado de la iniciativa del ALCA es que contribuyó a reavivar el interés de la UE por América Latina, sobre todo por el MERCOSUR. Esto se debe a que los países europeos no desean ver diluido su alto protagonismo histórico en la región frente al avance norteamericano, y en consecuencia intentan estrechar sus vínculos políticos y económicos con la ella.

El Tratado que en 1957 dio origen a la Comunidad Económica Europea (CEE) estableció, en sus artículos 110-116, los lineamientos para una política comercial común, que fueron recogidos sin mayores cambios en el Tratado de Maastricht sobre la Unión Europea. Dicha política comercial común tiene como objetivo formal contribuir a la gradual eliminación de las restricciones en el comercio internacional. Las propuestas concretas al respecto son presentadas por la Comisión ante el Consejo, que las evalúa y, en caso de aprobarlas, faculta a la Comisión para iniciar las necesarias negociaciones en el marco de las directivas y facultades impartidas. Con este mandato del Consejo, la Comisión lleva adelante todas las negociaciones correspondientes al sector externo, incluidas las de la OMC, y celebra acuerdos comerciales con diferentes países y otras regiones de integración. Para poder proceder así, los países miembros han tenido que ceder a la Comisión la soberanía sobre el sector externo, quedando obligados a aceptar los resultados a los que la misma arribe en sus tratativas.

La política de comercio exterior de la UE (y antes de su conformación, de la CEE) se caracteriza por la existencia de una serie de acuerdos comerciales de trato preferencial con algunos países y grupos de países: los países de África, el Caribe y el Pacífico (países ACP), en virtud de estrechas y preferenciales relaciones comerciales que se forjaron en el pasado colonial; los países del Mediterráneo, en base a la preexistencia de relaciones comerciales particularmente estrechas originadas en la proximidad geográfica y a la tradición; y finalmente los países interesados en ingresar a la UE (en su mayoría pertenecientes a Europa central y oriental). Para 
América Latina, esta política de preferencias para con las citadas regiones ha tenido la consecuencia práctica de una notoria postergación de la región dentro del esquema de la política de comercio exterior de la UE. En efecto, la atención que demandan los propios problemas de profundización y ampliación de la UE, las tradicionales preferencias comerciales con ciertos grupos de países y la política fuertemente proteccionista en relación al agro, han impedido a la UE concretar acuerdos globales de asociación o cooperación con América Latina. Adicionalmente, las ya insuficientes relaciones comerciales entre las dos regiones sufrieron un deterioro por la crisis de la deuda que afectó a los países latinoamericanos a principios de los años 80 y la década perdida que le siguió.

Con vistas a estudiar y procurar revertir estas carencias en la vinculación económica entre Europa y América Latina, en 1963 se creó una Comisión Especial de Coordinación Latinoamericana (CECLA) por encargo de la UNCTAD, que a través de su Carta de Buenos Aires planteó los reclamos de América Latina por el insuficiente diálogo económico y político con la CEE. Esta demostró su interés declarando a 1971 como el "año latinoamericano"; no obstante, su política para el Tercer Mundo, iniciada un año después, hizo imposible celebrar acuerdos sobre preferencias con países latinoamericanos, quedando limitado este tipo de acuerdos a los países ACP. Los países latinoamericanos tuvieron que conformarse con acuerdos bilaterales no preferenciales ${ }^{46}$, contratos de cooperación ${ }^{47}$ y algunos otros acuerdos muy puntuales ${ }^{48}$.

En resumen, se puede afirmar que debido a la ausencia de una estrategia de la UE en su comercio con América Latina y a la falta de consenso de los diferentes países latinoamericanos frente a la misma, la política europea para América Latina permaneció largo tiempo sumida en un estado de letargo. Sólo a partir de 1990 la UE inició un diálogo político y económico institucionalizado con el Grupo de Río, formado por Argentina, Brasil, Chile, Colombia, Ecuador, México, Paraguay, Perú, Uruguay y Venezuela ${ }^{49}$. Una nueva iniciativa de la UE tuvo lugar en 1995 cuando celebró con el MERCOSUR un acuerdo marco que prevé la creación de una zona de libre comercio entre ambos bloques, incorporando también a Chile, Bolivia y Venezuela.

Superados los efectos negativos de la crisis de la deuda y luego de que la mayoría de los países latinoamericanos implementara una política económica y de estabilización neoliberal y una apertura de sus mercados, a la vez que consolidaba la democracia, se manifestaba en América Latina una nueva situación. La caída en el déficit fiscal y en las tasas de inflación y la estabilización de los tipos de cambio, junto a la privatización de empresas públicas y la desregulación de los mercados, generaron un nuevo escenario económico. Luego de una retracción del producto bruto interno real en la mayoría de los países de la región como consecuencia de la crisis de la deuda, en la década del 90 se registró una aceleración de las tasas de crecimiento, juntamente con incrementos en el volumen del comercio exterior y en los flujos de IED. La apertura de los mercados latinoamericanos para recibir importaciones e inversiones directas desde terceros países creó nuevos incentivos a la exportación para las empresas europeas, y también para la instalación de centros de producción en la región ${ }^{50}$. América Latina se

\footnotetext{
${ }^{46}$ La CEE firmó este tipo de acuerdos con Argentina en 1971 y 1990 y con Brasil y Uruguay en 1973 y 1991.

${ }^{47}$ Se firmaron con México en 1975, con Brasil en 1980, con los estados centroamericanos en 1985 y con el Pacto Andino en 1987.

${ }^{48}$ En 1963 y 1965 se firmaron acuerdos sobre el uso pacífico de la energía nuclear con Argentina y Brasil, respectivamente.

${ }^{49}$ Sin embargo, por el momento este diálogo no ha cristalizado en resultados comerciales, al igual que ocurre con el diálogo entablado entre la UE y el Pacto Andino.

${ }^{50}$ El MERCOSUR y el NAFTA son dos zonas americanas de integración que suscitaron un fuerte interés europeo, como importantes mercados potenciales para sus productos.
} 
transformó en un mercado emergente, centro de una nueva ola de crecimiento internacional. Por otro lado, también los países latinoamericanos y sus diversas formas de integración económica comprendieron las ventajas de una mayor integración en el comercio mundial y de una inserción más activa en la división internacional del trabajo.

Ante esta realidad, se realizaron algunos intentos poco concretos para liberalizar y promover el comercio exterior entre la UE y América Latina, que no obstante las empresas y gobiernos aprovecharon para intensificar, dentro de sus posibilidades, sus relaciones económicas y comerciales, generando así una integración de hecho ${ }^{51}$ (ver Cuadros 6 y 7 del Apéndice Estadístico). En efecto, la UE comenzó a promover las relaciones económicas con América Latina, a través de acuerdos de cooperación comercial no preferenciales, convenios económicos diversos y de asistencia financiera y tecnológica para el desarrollo. Todo esto generó un renovado interés en las empresas europeas por la actuación en el mercado latinoamericano, aunque la persistencia de los subsidios agrícolas rígidamente afirmados en el corazón de la Política Agrícola Común de la UE han impedido el logro de metas de integración importantes.

\section{CONCLUSION}

A lo largo del trabajo se ha pretendido ofrecer un panorama de la situación del sector externo argentino en la actualidad ${ }^{52}$, así como un resumen de los principales acontecimientos que condujeron a la misma, con un enfoque teleológico. En virtud de esto último, el énfasis ha estado puesto en todo momento en los aspectos insatisfactorios de la realidad analizada y en las oportunidades para su modificación a través de la acción política.

Pasando ahora a considerar la situación específica de la Argentina en este nuevo contexto, lo primero que salta a la vista es que su frente de actuación es amplio: se trata de un país que ha encarado con determinación la tarea de adaptarse a la nueva economía global, implementando un programa de liberalización amplia y veloz, en todos los niveles en los que esto es posible: unilateral, multilateral y preferencial. Sin embargo, en su afán de realizar importantes cambios en escaso tiempo, tal vez en un intento por "recuperar el tiempo perdido" durante décadas de aislamiento y relativa autarquía, ha resignado planeamiento, organización y, sobre todo, el "hilo conductor" que brinda la existencia de una sólida estrategia nacional. En efecto, si bien los esfuerzos realizados en los distintos ámbitos de la política comercial son notorios, se advierte una falta de cohesión entre los mismos, a la cual contribuye la excesiva amplitud de la agenda planteada en relación a los recursos humanos, técnicos y financieros de los que dispone el país. Esto es particularmente evidente al observar los numerosos frentes de negociación preferencial en los que la Argentina se encuentra involucrada actualmente: MERCOSUR, ALCA, negociaciones con la UE, además de las numerosas negociaciones bilaterales en curso y las conversaciones que se ha empezado a mantener con potenciales socios no tradicionales para el país, tales como China y otros países asiáticos. Aún cuando la existencia de varias alternativas contribuye a reforzar la posición negociadora argentina en los distintos foros, el hecho de tener que actuar simultáneamente en varios ámbitos con una limitada cantidad de recursos de toda índole implica el riesgo de no poder defender los intereses nacionales de una manera adecuada. Ante esta situación, resulta evidente que la eliminación arbitraria y a priori de algunas de las alternativas

\footnotetext{
${ }^{51}$ Esta sencilla modalidad de integración consiste en que, en la medida en que las condiciones generales existentes no impliquen trabas comerciales o discriminaciones, las empresas extranjeras pueden aprovechar las oportunidades que ofrecen otros países para acceder a nuevos mercados y desarrollarlos, así como para reforzar su presencia en los mercados externos a través de inversiones directas, todo esto sin la existencia de un tratado formal de integración.

52 Se ha trabajado en términos de la economía real, tocando sólo marginalmente y a efectos de hacer más clara la exposición los aspectos de naturaleza monetaria.
} 
existentes no constituye una solución inteligente. Por el contrario, lo que se debe hacer es definir cuidadosamente una agenda estratégica de negociaciones, estableciendo prioridades de modo de poder concentrar en cada foro la mayor cantidad y calidad de recursos disponibles. Esto ayudará a reducir la evidente desventaja al negociar con países ricos y poderosos, que son mucho más fuertes que la Argentina en la arena diplomática, dado que disponen de mayores recursos humanos y materiales y de una larga tradición negociadora.

Cuando la negociación se lleva a cabo con países en un estadio de desarrollo similar al propio, esta desventaja en el proceso de negociación desaparece, pero en contrapartida, las posibilidades de alcanzar metas económicas importantes se reducen: como ya se señaló a lo largo del trabajo, la evidencia empírica muestra que este tipo de integración no conduce a la convergencia de ingresos con respecto a los niveles existentes en los países ricos. Por el contrario, la integración con países en un estadio de desarrollo avanzado es muy promisoria en este sentido, pero siempre y cuando los países menos desarrollados negocien adecuadamente y logren evitar el abuso de poder de las potencias, ya que si esto último se produce, los riesgos de quedar en una situación aún peor que la anterior son muy altos. Esto último es válido no sólo en el ámbito de la negociación preferencial sino también en el multilateral, como queda evidenciado por los pobres resultados que los países en desarrollo obtuvieron en la última rueda de negociación (Rueda Uruguay) y el severo desbalance en su contra.

Centrándose ya en el caso concreto de las negociaciones externas actuales de la Argentina, se pueden hacer varias precisiones.

Dentro del marco de la integración con otros países en desarrollo, se observa un éxito considerable del MERCOSUR, tanto en términos económicos como estratégicos. En lo relativo a los logros económicos, se destaca un muy importante aumento del comercio intra regional, sobre todo entre Argentina y Brasil, si bien no libre de vicisitudes, que se originan mayormente en la inestabilidad de los países miembros y en la falta de coordinación macroeconómica. De todos modos, a pesar de su relativo éxito, el MERCOSUR no deja de ser un acuerdo entre países emergentes, y en función de las metas de convergencia hacia los estándares de ingreso y desarrollo de los países avanzados, más que un fin en sí mismo debería ser considerado como un poderoso medio para negociar más ventajosamente con aquéllos. Por otra parte, el éxito desde el punto de vista estratégico ha resultado evidente en las negociaciones del ALCA, en las que el bloque ha podido mantener una postura en muchos aspectos enfrentada con la de EEUU, principal potencia del hemisferio y "padre" del proyecto. Asimismo, el MERCOSUR ha sido causa de un renovado interés de la UE por la región, que podría llegar a materializarse en algún tipo de acuerdo preferencial. No obstante, en la medida en que subsistan o, peor aún, se agraven las fallas de coordinación existentes entre los países miembros y sus problemas internos, propios de su condición de países emergentes, las bases del poder que les da el hecho de ser un bloque se van erosionando, y se corre el riesgo de que la agrupación termine siendo absorbida o pierda vigor.

Con respecto a las perspectivas de integración preferencial con países desarrollados, las posibilidades de la Argentina se vinculan básicamente al proyecto del ALCA y a las negociaciones con la UE.

El proyecto del ALCA, como se dijo en la correspondiente sección del trabajo, puede ser considerado como la respuesta de EEUU frente al nuevo panorama mundial de los 90, uno de cuyos factores fue la creciente importancia de América Latina y sobre todo de los países del MERCOSUR. En términos políticos y estratégicos, el ALCA tiene una gran importancia ya que se trata de una inédita invitación de EEUU a los países de América Latina para negociar como pares, aunque, evidentemente, este emparejamiento es más formal que real. Otra peculiaridad con 
respecto a las anteriores relaciones entre EEUU y América Latina es que en este caso los temas económicos han tomado muy claramente (en opinión de algunos, demasiado) la delantera con respecto a la visión política, lo cual está relacionado con el resurgimiento económico de la región en los años 90.

La principal ventaja que ofrece el ALCA es un potencial acceso al inmenso mercado norteamericano, formado por millones de habitantes con un alto poder adquisitivo. Sin embargo, los riesgos son grandes y diversos, incluyendo probables problemas de desvío de comercio, debilitamiento y eventual dilución de los esquemas de integración entre países latinoamericanos (incluido el MERCOSUR) y virtual eliminación de oportunidades interesantes de vinculación económica con otros países y regiones con las que la Argentina está comenzando a relacionarse con una mayor intensidad (como China y otros países asiáticos).

En lo tocante a las negociaciones con la UE, las oportunidades de llegar a un acuerdo ventajoso se ven severamente obstruidas por el persistente proteccionismo agrícola de los europeos, que perjudica enormemente los intereses de los países latinoamericanos, productores eficientes de este tipo de bienes. Sin embargo, dado el potencial de consumo de Europa, vale la pena seguir analizando la posibilidad e intentar presionar, en la medida de lo posible, en pro de una mayor liberalización en el rubro agropecuario.

Puede afirmarse que la Argentina tiene abiertas una serie de oportunidades interesantes, pero que fácilmente pueden volverse en su contra si no logra negociar con firmeza, en función de prioridades preestablecidas. Para que esto último sea posible resulta prioritario una revalorización de la política comercial, frecuentemente relegada en virtud del excesivo énfasis que los argentinos solemos poner en la política interna, y sobre todo en el logro del equilibrio fiscal estático. Al hacer esto, olvidamos lo crucial que resulta desarrollar una adecuada política de inserción en los mercados externos, ya que la inversión y la exportación son los canales a través de los cuales los países logran el crecimiento del producto y la generación de divisas, sobre todo en el caso de las economías pequeñas, con un mercado interno reducido. Con esto no se pretende negar la indudable importancia de las políticas fiscal y monetaria, sino más bien recalcar que la creación de una adecuada red de relaciones comerciales con otras economías, conformada a través de una estrategia coherente de inserción externa, resulta indispensable para alcanzar la codiciada meta de ingresar, en algún futuro, en un sendero de crecimiento sostenido.

\section{BIBLIOGRAFÍA}

Bhagwati, Jagdish (1993): Regionalism and Multilateralism: An Overview, en New Dimensions in Regional Integration, Jaime de Melo y A. Panagariya eds., London, Centre for Economic Research, 1993.

Bhagwati, Jagdish y Arvind Panagariya (1996): "Preferential Trading Areas and Multilateralism: Strangers, Friends or Foes?”, en The Economics of Preferential Trade Agreements, J. Bhagwati y A. Panagariya eds., Washington, D.C., American Enterprise Institute Press, 1996.

Briceño Ruiz, José (2001): "El MERCOSUR, México y el Caribe frente al Area de Libre Comercio de las Américas”, Comercio Exterior, Vol. 51, Nº 5, mayo 2001.

Coe, David T., Elhanan Helpman and Alexander W. Hoffmaister (1997): "North-South R\&D Spillovers”, Economic Journal 107 (1997): 134- 149.

Damill, Mario y Daniel Kampel (1999): “Acerca de la evolución de la prima de riesgo de la deuda soberana de la Argentina”, Universidad de Palermo, mayo 1999.

Devlin, Robert y Luis Jorge Garay (1996): "De Miami a Cartagena: nueve enseñanzas y nueve desafíos del ALCA”, Contribuciones, 4/96. 
Eaton, Jonathan y Kortum, Samuel (1997a): "Engines of Growth: Domestic and Foreign Sources of Innovation", Japan and the World Economy 9 (1997): 235-259.

Eaton, Jonathan y Kortum, Samuel (1997b): “Technology and Bilateral Trade”, NBER Working Paper $N^{\circ} 6253$ (November 1997). Sitio Web: www.nber.org

Eaton, Jonathan y Kortum, Samuel (2001): “Trade in Capital Goods”, NBER Working Paper No 8070 (January 2001). Sitio Web: www.nber.org

Fernández, Raúl y Gustavo González (1996): “La coordinación de políticas macroeconómicas y el MERCOSUR”, Contribuciones, 4/96.

Hufbauer, Gary y Barbara Kotschawar (1996): "Un proceso frenado: la política de EEUU frente a América Latina”, Contribuciones, 4/96.

Kahler, Miles (1995): "Internacional Institutions and the Political Economy of Integration", Washington, D.C., The Brookings Institution, 1995.

Krugman, Paul R. y Maurice Obstfeld (1999): "Economía Internacional. Teoría y política”, Cuarta edición, McGraw-Hill/Interamericana de España, S.A.U., 1999.

Nofal, María Beatriz (1997): "Las grandes asignaturas pendientes del MERCOSUR: alternativas ¿profundización o dilución?”, Boletín Informativo Techint, $\mathrm{N}^{\circ}$ 292, octubre-diciembre 1997.

Nogués, Julio (2001): "La «institucionalización» de la globalización: negociaciones comerciales, bloques económicos", en "La globalización, la Argentina y cada uno de nosotros", Consejo Empresario Argentino, Buenos Aires, 2001.

Rapoport, Mario et. al. (2000): "Historia económica, política y social de la Argentina (18802000)”, Ediciones Macchi, Buenos Aires, 2000.

Schaal, Peter (1996): "La posición de la Unión Europea frente a los nuevos procesos de integración en América Latina”, Contribuciones, 4/96.

Srnivasan, T.N. (1998): “Regionalism and the WTO: Is Nondiscrimination Passé?”, en The WTO as an International Organization, Anne O. Krueger ed., Chicago, University of Chicago Press, 1998.

Svarzman, Gustavo (1998): "La Argentina y el MERCOSUR ante el proceso de integración hemisférica”, Boletín Informativo Techint, № 295, julio-septiembre 1998.

Von Wuthenau, Celedonio (1996): "Los procesos de integración interestatales en el continente americano", Contribuciones, 4/96.

Winham, G.R. (1986): “International Trade and the Tokio Round Negotiation”, Princeton, New Jersey, Princeton University Press, 1986.

World Bank (2001): “Trade Blocs”, Oxford University Press, 2001. 
Gráfico 1. Riesgo país y crecimiento económico

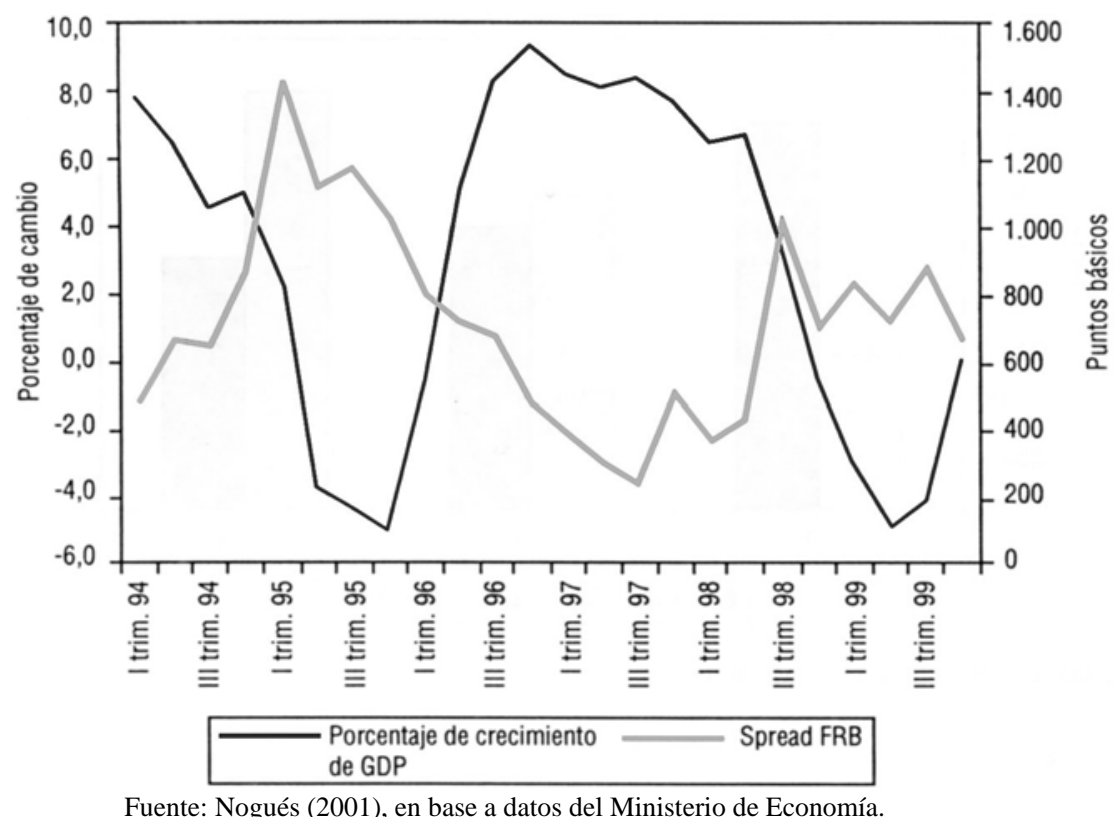

Fuente: Nogués (2001), en base a datos del Ministerio de Economía.

Gráfico 2. Número de acuerdos de integración regional notificados al GATT entre 1948 y 1997

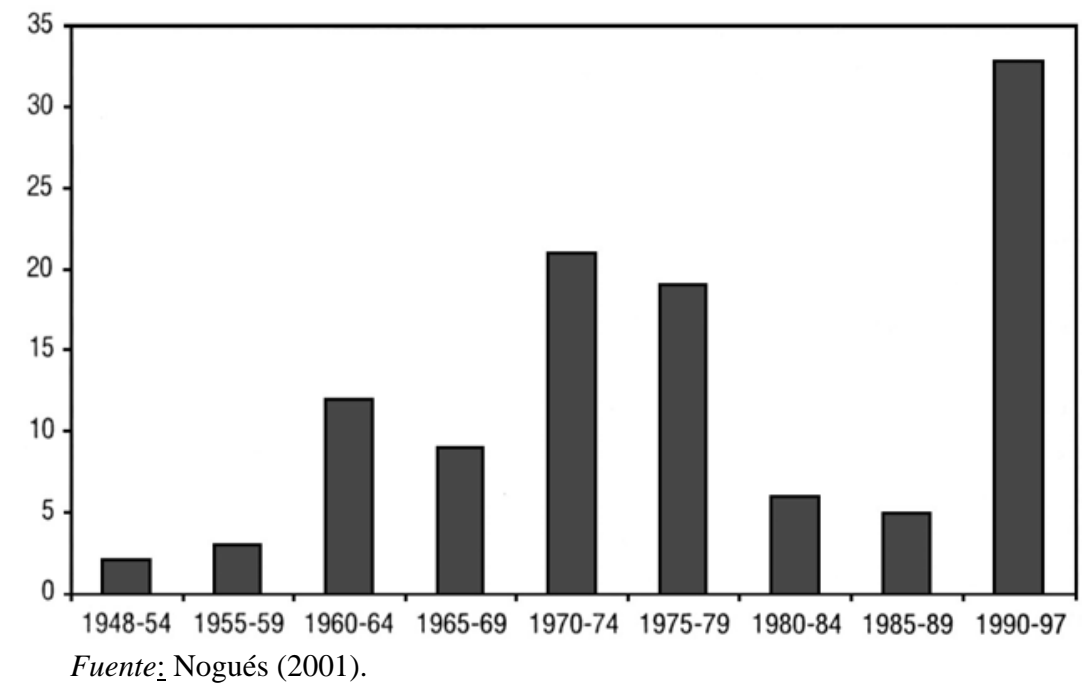


Cuadro 1. Comercio Argentina - Brasil (1987-1998)

$\begin{array}{llllllllllll}1987 & 1988 & 1989 & 1990 & 1991 & 1992 & 1993 & 1994 & 1995 & 1996 & 1997 & 1998\end{array}$

\begin{tabular}{|c|c|c|c|c|c|c|c|c|c|c|c|c|}
\hline Importacion del Brasil ( $\left.{ }^{1}\right)(A)$ & 831,8 & 979,4 & 722,1 & 645,1 & 1476,2 & $3.040,0$ & $3.658,8$ & 4.135,9 & $4.041,1$ & $5.170,0$ & $6.767,3$ & $6.747,1$ \\
\hline Variación relativa & - & 17,75 & $-26,27$ & $-10,66$ & 128,81 & 105,94 & 20,36 & 13,04 & $-2,29$ & 27,94 & 30,89 & $-0,30$ \\
\hline Participac, en las importac, totales argentinas (\%) & 14,29 & 18,40 & 17,19 & 15,82 & 17,84 & 20,44 & 21,80 & 19,16 & 20,08 & 21,76 & 22,12 & 21,49 \\
\hline Participac, en las exportac, totales brasileñas (\%) & 3,17 & 2,90 & 2,10 & 2,05 & 4,67 & 8,49 & 9,49 & 9,50 & 8,69 & 10,83 & 12,77 & 13,20 \\
\hline Exportaciones al Brasil (2) (B) & 574,69 & 707,10 & 1238,99 & 1399,68 & 1614,68 & 1731,63 & 2717,27 & $3.661,97$ & $5.591,39$ & $6.805,47$ & $7.941,29$ & $8.034,17$ \\
\hline Variación relativa & - & 23,04 & 75,22 & 12,97 & 15,36 & 7,24 & 56,92 & 34,77 & 52,69 & $\mathbf{2 1 , 7 1}$ & 16,69 & 1,17 \\
\hline Participac, en las exportac, totales argentinas (\%) & 9,04 & 7,74 & 12,94 & 11,33 & 13,48 & 14,15 & 20,76 & 23,12 & 26,67 & 28,58 & 30,27 & 30,39 \\
\hline Participac, en las importac, totales brasileñas (\%) & 3,82 & 4,84 & 6,79 & 6,77 & 7,67 & 8,42 & 10,76 & 11,07 & 11,19 & 12,76 & 13,29 & 13,92 \\
\hline Corriente de comercio $(A+B)$ & 1406,47 & 1686,49 & $1.961,10$ & 2044,82 & $3.090,85$ & $4.771,61$ & $6.376,05$ & $7.797,83$ & $9.632,53$ & 11975,50 & $14.708,56$ & $14.781,28$ \\
\hline Balanza comercial argentina total & 541 & 3.813 & 5.373 & 8.275 & 3.703 & -2635 & -325 & -5.751 & 841 & 49 & -4.019 & -4.963 \\
\hline
\end{tabular}

Fuente: Rapoport, Mario et. al. (2000), en base a datos de INDEC, FIDE y Ministerio de Desenvolvimiento, Industria e Comércio de Brasil.

Cuadro 2. Exportaciones de EEUU a principales países y regiones

\begin{tabular}{lcccc}
\hline Países / Regiones & 1990 & 1997 & Var. & $\begin{array}{c}\text { Contribución } \\
\text { al incremento }\end{array}$ \\
\hline Unión Europea & 103.588 & 140.803 & $35,9 \%$ & $12,6 \%$ \\
América Latina & 51.460 & 134.412 & $161,2 \%$ & $28,1 \%$ \\
NIC'́s Este Asia & 40.556 & 78.297 & $93,1 \%$ & $12,8 \%$ \\
Japón & 48.585 & 65.673 & $35,2 \%$ & $5,8 \%$ \\
A. Latina excl. México & 26.491 & 63.034 & $137,9 \%$ & $12,4 \%$ \\
MERCOSUR & 6.693 & 21.720 & $24,5 \%$ & $5,1 \%$ \\
China & 4.807 & 12.805 & $166,4 \%$ & $2,7 \%$ \\
Australia & 8.602 & 12.041 & $40,0 \%$ & $1,2 \%$ \\
Europa del Este & 5.753 & 7.722 & $34,2 \%$ & $0,7 \%$ \\
Sudáfrica & 1.732 & 3.001 & $73,3 \%$ & $0,4 \%$
\end{tabular}

Fuente: Svarzman, Gustavo (1998), en base FMI (1997) y U.S. NTDB (1998).

Cuadro 3. Corrientes de IED hacia América Latina, 1990-1994

\begin{tabular}{|c|c|c|c|c|c|c|}
\hline Fuente & 1990 & 1991 & 1992 & 1993 & 1994 & $\begin{array}{c}\text { Crecimiento } \\
\text { anual promedio }\end{array}$ \\
\hline $\begin{array}{l}\text { EE.UU. } \\
\text {. }\end{array}$ & 3217 & 4970 & 5568 & 8325 & 11582 & $38 \%$ \\
\hline Unión Europea & 1730 & 1271 & 1398 & 916 & 4446 & $27 \%$ \\
\hline Japón & 399 & 561 & 270 & 132 & 568 & $9 \%$ \\
\hline
\end{tabular}

Fuente: Hufbauer, Gary y Barbara Kotschwar (1996). 
Cuadro 4. Productividad del trabajo en América Latina como porcentaje de la correspondiente a EEUU, año 1990

Principales ramas de la industria

Refinerías de Petrólio

$76,1 \%$

Metales no Ferrosos

$56,1 \%$

Productos de Caucho

$41,3 \%$

Hierro y Acero

$40,9 \%$

Textiles

$36,6 \%$

Maquinaria Eléctrica

$28,5 \%$

Material de Transporte

$25,4 \%$

Papel y Celulosa

$25,1 \%$

Productos Alimenticios

$18,1 \%$

Total industria

$26,1 \%$

Fuente: Svarzman, Gustavo (1998), en base a CEPAL.

Cuadro 5. Estructura arancelaria de los principales países del ALCA

\begin{tabular}{lcc}
\hline País & Arancel & \\
México & Medio* & Desvio Estándar \\
Argentina & $15,4 \%$ & 12,5 \\
Brasil & $13,6 \%$ & 7,4 \\
Colombia & $12,7 \%$ & 9,8 \\
Chile & $11,4 \%$ & 6,5 \\
MCCA & $11,0 \%$ & 0,7 \\
Canadá & $10,1 \%$ & 7,5 \\
EE.UU. & $6,7 \%$ & 6,9 \\
\end{tabular}

* Aranceles NMF promedio Simple

Fuente: Svarzman, Gustavo (1998), en base a BID (1997) y IECD (1997).

Cuadro 6. Comercio de la UE con el MERCOSUR, el Grupo Andino y Chile 1990-1995

\begin{tabular}{|c|c|c|c|c|c|c|c|}
\hline & 1990 & 1991 & 1992 & 1993 & 1994 & 1995 & $\begin{array}{c}\text { Crecimiento } \\
\text { promedio } \\
\text { anual 1990-95 }\end{array}$ \\
\hline \multicolumn{8}{|l|}{ MERCOSUR } \\
\hline Exportaciones de la UE al MERCOSUR & 6774 & 7548 & 8872 & 11206 & 14770 & 18061 & $21,7 \%$ \\
\hline Importaciones desde el MERCOSUR & 17225 & 18013 & 16809 & 14698 & 17640 & 20995 & $4,0 \%$ \\
\hline Comercio de la UE con el MERCOSUR & 23999 & 25561 & 25681 & 25904 & 32410 & 39056 & $10,2 \%$ \\
\hline \multicolumn{8}{|l|}{ COMUNIDAD ANDINA } \\
\hline Exportaciones de la UE al Grupo Andino & 4212 & 4638 & 5492 & 5152 & 5477 & 7151 & $11,2 \%$ \\
\hline Importaciones del Grupo Andino & 5662 & 5626 & 5715 & 4911 & 6266 & 7551 & $5,9 \%$ \\
\hline Comercio de la UE con el Grupo Andino & 9874 & 10264 & 11207 & 10063 & 11743 & 14702 & $8,3 \%$ \\
\hline
\end{tabular}


CHILE

\begin{tabular}{|c|c|c|c|c|c|c|c|}
\hline Exportaciones de la UE hacia Chile & 1495 & 1416 & 1874 & 1992 & 2189 & 4448 & $24,4 \%$ \\
\hline Importaciones de Chile & 3251 & 3166 & 3071 & 2557 & 2937 & 3173 & $-0,5 \%$ \\
\hline Comercio de la UE con Chile & 4746 & 4582 & 4945 & 4549 & 5126 & 7621 & $9,9 \%$ \\
\hline
\end{tabular}

Fuente: Hofbauer, Gary y Barbara Kotschwar (1996).

Cuadro 7. IED de la UE en América Latina

\begin{tabular}{lcccccc}
\hline & 1990 & 1991 & 1992 & 1993 & 1994 & $\begin{array}{c}\text { Crecimiento } \\
\text { anual promedio }\end{array}$ \\
\hline MERCOSUR & 1125 & 988 & 801 & 447 & 1449 & $7 \%$ \\
Grupo Andino & 103 & 167 & 174 & 56 & 1872 & $106 \%$ \\
Grupo de los Tres & 1125 & 988 & 801 & 447 & 1449 & $7 \%$ \\
Centro América & 6 & 15 & 23 & 16 & 23 & $40 \%$
\end{tabular}

Fuente: Hofbauer, Gary y Barbara Kotschwar (1996). 